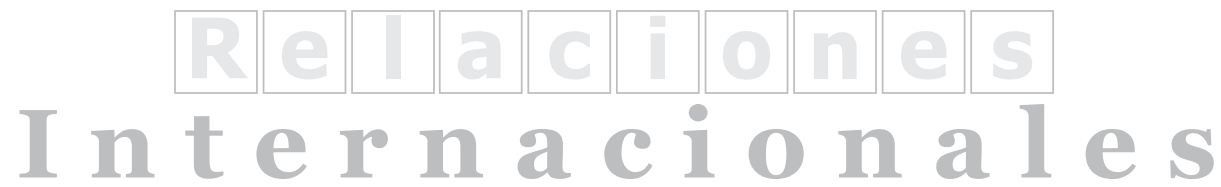





\section{El proceso de construcción de normas sistémicas visto desde una epistemología genética neoconstructivista basada en Jean Piaget*}

\section{The Construction Process of Systemic Norms Seen from a Genetic Neoconstructivist Epistemology Based on Jean Piaget}

\section{Ángel Sánchez Mendioroz ${ }^{* *}$}

Recibido: 30 de octubre 2015

Aprobado: 21 de enero de 2016

Disponible en línea: 30 de junio de 2016

\section{Resumen}

Los procesos de globalización y de regionalización en el mundo exigen nuevas formas de regulación, las cuales deberán superar, coordinar y organizar las estructuras normativas institucionales actuales características de la modernidad. El presente trabajo es un ensayo epistemológico, basado en Jean Piaget, que propone la necesidad de ampliar las actuales estructuras normativas y pasar de un estadio institucional-moderno a un estadio sistémico-posmoderno. Esta propuesta está basada, primero, en la existencia de estadios sociocognitivos que determinan las características esenciales de toda estructura social de regulación. Segundo, en el surgimiento y en la construcción global de un nuevo estadio

\section{Abstract}

The processes of globalization and regionalization worldwide require new forms of regulation, which must overcome, coordinate and organize the current institutional normative structures characteristic of modernity. The present work is an epistemological essay, based on Jean Piaget, that proposes the need to extend the current normative structures, namely moving from an institutional modern stage to a postmodern systemic stage. This proposal is based, first, on the existence of sociocognitive stages that determine the essential characteristics of any social structure of regulation. Second, the proposal is based on the global construction of a new stage of sociocognitive regulatory structures:

doi:10.11144/Javeriana.papo21-1.pcns

* Artículo de reflexión.

* Doctor rerum naturalium en Psicología Cognitiva (Univ. Leipzig, Alemania). Psicoterapeuta constructivista-sistémico. Coach Psicológico de empresas y organizaciones privadas. Psicológo Deportivo. Director de un instituto de terapia familiar-sistémica. Investigador independiente. Residencia en la República Federal Alemana. Email:angel.sanchez@gmx.de 
sociocognitivo de estructuras regulativas: el the constructivist-systemic stage. Third, the estadio constructivista-sistémico. Tercero, el enfoque predice el surgimiento de una nueva estructura estatal con carácter sistémico: el Estado internacional. Esta nueva estructura de gobernanza sistémica deberá poder surgir solo sobre la base de las estructuras institucionales de normación del actual Estado-nación. El análisis metodológico neopiagetiano -con carácter dialéctico- que expone este artículo pretende demostrar la tesis sociocognitiva mencionada.

\section{Palabras clave}

neoconstructivismo; estadios sociocognitivos; estructuras normativas; equilibración (autoorganización); asimilación-acomodación; centralización-descentralización; Estado internacional approach predicts the emergence of a new state structure with a systemic character: the International-State. This new structure of systemic governance would only be able to arise on the basis of the institutional normation structures of the current nation-state. The neopiagetian methodological analysis - with dialectical character - that this article exposes aims to demonstrate the mentioned sociocognitive thesis.

\section{Keywords}

neoconstructivism; sociocognitive states; normative structures; equilibration (self-organization); assimilation-accommodation; centralization and decentralization; international state

\section{Cómo citar este artículo:}

Sánchez-Mendioroz, A. (2016). El proceso de construcción de normas sistémicas visto desde una epistemología genética neoconstructivista basada en Jean Piaget. Papel Político, 21(1), 123-166. http://dx.doi.org/10.11144/ Javeriana.papo21-1.pcns 


\section{Introducción}

El presente artículo trata sobre el organismo humano visto como actividad normativa. Sin embargo, no se trata de la actividad normativa que el ser humano realiza, sino de la actividad normativa que él mismo es. Esta perspectiva organísmica del ser humano se basa en dos conceptos básicos: la idea del constructivismo (personas o sistemas construyen la realidad en que viven) y la idea del desarrollo (los sistemas orgánicos se desarrollan sistemáticamente durante estadios alternados de estabilidad y transformación). Ambos conceptos remarcan de manera diferente que detrás de cada norma o sistema normativo se oculta un proceso evolutivo, que es el que la crea o la deja surgir. En nuestro estudio, nos basamos en Piaget (1964a, 1965, 1970a, 1971a, 1972, 1973, 1976, 1983), debido a que su genialidad radica en haber encontrado la solución para unir ambos conceptos en una teoría congruente y clara. Piaget se apasionó por dos temas: la filosofía (epistemología: construcción del conocimiento) y la biología (genética: desarrollo evolutivo). El resultado es su epistemología genética-estructural (Piaget, 1965, 1970a).

La epistemología genética-estructural de Piaget parte del supuesto de la existencia de un sistema autorregulador en el organismo (estructuras cognitivas), de carácter neurobiológico y cuyos elementos estarían constituidos por esquemas cognitivos. En el presente trabajo, se defiende la hipótesis de que las normas sociales no vendrían a ser otra cosa que el equivalente de dichas estructuras cognitivas; sin embargo, con una diferencia, y es que las estructuras normativas sociales vendrían a representar una función cognitiva ampliada del organismo humano, la que estaría a cargo de la regulación de las interacciones normativas que tienen lugar entre los agentes sociales. El concepto cognición, utilizado aquí, se diferencia, entonces, del uso que se le da en la filosofía, psicología y sociología modernas, en las cuales está separado del comportamiento organísmico. En el concepto piagetiano, una cognición (operación) representa la actividad concreta (comportamiento = conocimiento) de un organismo cualquiera (biológico o social) y, por ende, un sistema cognitivo es un sistema comportamental, cuya estructuración interna define el campo interactivo donde deberá operar el organismo, siempre con el objetivo de la autoconservación (Piaget, 1971a).

Partiendo de los supuestos anteriores, las estructuras normativas no son, de esta manera, simplemente el producto de una percepción pasiva de la realidad externa, sino que representan más bien estructuras autorreguladoras autónomas, y con cuya ayuda el organismo social aspira a controlar (asimilar) su entorno (en concordancia con sus necesidades de autoconservación). Son estas estructuras normativas internas las que en última instancia dirigen el comportamiento y las acciones de todos los organismos sociales, vistos como sistemas. De esta manera, podemos hablar de estructuras normativas 
homeostáticas y morfogenéticas. ${ }^{1}$ A lo interno de un sistema cualquiera, las estructuras homeostáticas son aquellas estructuras normativas de autoconservación que presentan los sistemas sociales y las cuales exigen - respectivamente esperan de sus miembrosel cumplimiento de compromisos establecidos anteriormente por ellos mismos. Las estructuras normativas morfogenéticas, por el contrario, reflejan el comportamiento adaptativo concreto que presentan los miembros de cualquier organismo o sistema social y el cual puede o corresponderse o apartarse de las normativas establecidas. Las estructuras normativas morfogenéticas vendrían a ser, así, procesos autorreferenciales que presentan en forma individual los miembros de un sistema social, y que conllevan la construcción de estructuras de regulación propias. Sirva de ejemplo el actual conflicto normativo entre Grecia, con un comportamiento guiado por estructuras normativas morfogenéticas y las expectactivas del resto de países miembros de la Comunidad Europea, las que se orientan sobre el cumplimiento de normativas homeostáticas.

\section{Metodología}

La metodología que se utiliza en el enfoque presentado en este trabajo es de carácter dialéctico y se basa en los postulados y principios de la epistemología genética de Piaget (1970a). Sin embargo, se trata de una dialéctica vista, no solo como método, sino también como proceso; es decir, si le aplicamos el principio de circularidad constructivista piagetiano, vemos que ella es al mismo tiempo capaz de estudiarse a sí misma y nos muestra así su propio desarrollo histórico-dialéctico que oscila entre posiciones idealistas y materialistas.

El término dialéctica proviene del griego (dialektiké/téchnē) que significa técnica de la disputa (argumentar), es decir, el proceso de la búsqueda de la verdad a través de disputar socialmente. Platón y Aristóteles utilizaron la dialéctica de manera idealista, respectivamente naturalista, para clarificar conceptos difusos y corregir errores argumentativos. El escolástico Boethius liberó a la dialéctica de ser solo un método de control y correctura dándole además la función heurística de encontrar nuevos puntos de vista y opinión, los que a continuación deberán ser puestos a prueba dialécticamente (Schwemmer, 1980).

Kant agregó a la dialéctica una nueva significación. Para él, la dialéctica era una manera de exponer la relación entre Sujeto y Objeto durante el proceso del conocer (Schwemmer, 1980). Hegel utilizó, al igual que Husserl más tarde, la reflexión dialéctica, a fin de eliminar todos los prejuicios subjetivos en el proceso de conocer algo y de esta manera poder reconstruir el desarrollo histórico del concepto correspondiente a ese algo. Así es que puede reconstruirse el movimiento de la "cosa en sí”, ya que el "desarrollo histórico se da solo por conocido, cuando este se expone no solo como sucesión

\footnotetext{
${ }^{1}$ Diferenciación o contradicción entre estructuras normativas establecidas (homeostasis) y estructuras normativas en desarrollo (morfogénesis) dentro de un sistema social cualquiera. Al proceso de coordinación entre ambas formas normativas se le llama proceso de equilibración o evolutivo.
} 
de acontecimientos sino como desarrollo de conceptos o categorías [La traducción es mía]" (Schwemmer, 1980, p. 466).

Con la evolución teórica anterior, se le vino a dar a la postulación dialéctica -antes solo teoría de la argumentación - una connotación completamente nueva, a saber una que la convierte en teoría del desarrollo. Esta nueva connotación aparece todavía más fuerte en la posición de Marx, ya que este no establece ahora las categorías como punto de partida del movimiento de la "cosa en sí", sino la realidad social - determinada por nuestras necesidades y por la organización social para satisfacerlas- (Schwemmer, 1980). Engels fue todavía un poco más allá y contrapuso su “dialéctica objetiva” a la “dialéctica subjetiva” de Hegel. La dialéctica de Engels ya no solo era válida para explicar el desarrollo social, sino para todos los acontecimientos naturales y sociales (Schwemmer, 1980). De esta manera, encontramos una diferencia entre el idealismo dialéctico de Hegel y el materialismo dialéctico de Marx y Engels. Según el idealismo dialéctico, el desarrollo marcha en una dirección teleológica, es decir, con un fin determinado, lo cual significa que en un determinado momento podría alcanzar su meta y terminar. Según el materialismo dialéctico, la contradicción, vista como ley del desarrollo, solo puede tener lugar en forma empírica y no categorial; por esta razón, ella sirve solo para la explicación de hechos y no para su predicción, con lo que el desarrollo no vendría a tener ni meta ni un final (Reese, 1982).

¿En qué consiste, según estos filósofos, la ley del desarrollo dialéctico? En la contradicción. Hegel formuló el famoso triple paso: tesis-antítesis-síntesis. Según este, cada acto del conocer (tesis) provoca una contradicción (antítesis). En el transcurso de su disputa, ambas conservarán una relativa validez, por lo que ellas al final desembocarán en una síntesis (nueva tesis) a un nivel cualitativo superior. Según Engels, existen tres leyes dialécticas: el traspaso de cantidad en calidad o de saltos cuantitativos a cualitativos, la interpenetración mutua de los polos contrapuestos y su transformación interna o de lucha de contrarios y el desarrollo por contradicción o negación de la negación (Schwemmer, 1980). Otros pensadores prominentes del desarrollo dialéctico en el bloque soviético fueron Vygotsky (1896-1934), Rubinstein (1889-1960), Luria (1902-1977) y Leontjew (1903-1979). Contemporáneamente, Theodor W. Adorno (1903-1969), representante de la escuela neomarxista de Fráncfort, subraya la posición materialista y el carácter inconcluso de cualquier momento del movimiento de contraposición (contradicción), tanto en el nivel social como cultural.

El punto común de la dualidad dialéctica (materialismo-idealismo) de las posiciones teóricas anteriores es que todas parten de una realidad estática, ya de un mundo material regido por leyes naturales fijas, ya de un mundo de las ideas, también con carácter inamovible y eterno. Lo nuevo de la dialéctica epistemológica genética de Piaget (1970a) es su carácter constructivista e interaccionista. Al materialismo empirista Piaget lo ha llamado "génesis sin estructuras" (evolución sin ideas) y al idealismo apriorista “estructuras sin génesis" (ideas sin evolución). Frente a estas dos soluciones históricas, 
Piaget sostiene la postura propia de que no existen estructuras que no provengan de otras estructuras, es decir, sin génesis, y de que toda génesis o desarrollo requiere una estructura previa. A su entender, el origen del conocimiento (estructuras normativas) no se explica suficientemente ni a partir solo del objeto (materia) ni solo del sujeto (ideas), constituidos, y vistos ambos de forma independiente el uno del otro. Según Piaget, tanto el sujeto (agente o estructuras internas) como el objeto (estructuras externas) del conocimiento vendrían a construirse mutuamente a través de la interacción adaptativa que ocurre entre ambos y la cual es la base de la realidad que conocemos, a saber, una realidad que no es otra cosa que una construcción en constante evolución, resultado de las interacciones dialécticas entre el sujeto y el objeto del conocimiento.

La idea fundamental de la epistemología genética consiste, entonces, en que el conocimiento no es otra cosa que un fenómeno adaptativo, el cual surge genéticamente de la relación en constante desarrollo que tiene lugar entre el organismo humano (sociedad) y su contexto de referencia (naturaleza). En ese intercambio dialéctico, consiste exactamente el proceso adaptativo biológico, que en el aspecto social y mental no es otra cosa que el desarrollo progresivo de la inteligencia y la sociedad humana. El conocimiento, y con esto el desarrollo normativo, vendría a manifestarse, según esta teoría, en forma de una sucesión de estructuras epistémicas, a las que nosotros llamamos estructuras sociocognitivas de normativización y las cuales se desprenden unas de otras.

\section{Objetivo}

El objetivo central de este trabajo es el de presentar una propuesta teórica consistente - de carácter organísmico- sobre cómo tiene lugar todo desarrollo normativo dentro de los organismos sociales. Dicha propuesta persigue, por un lado, demostrar la necesidad de superar activamente posiciones teóricas positivistas y racionalistas sobre el proceso de formación normativo, características de la modernidad y las que actualmente no están contribuyendo a enfrentar las necesidades urgentes de regulación de un mundo cada vez más globalizado, cuya complejidad, en constante aumento, exige perspectivas de normación más viables y flexibles. Por otro lado, dicha propuesta deberá servir de instrumento teórico de análisis, y por qué no, también de intervención, en la medida en que ayude a entender los procesos de transformación y de construcción del nuevo estadio sociocognitivo, que es característico de la posmodernidad, y al cual hemos llamado el estadio constructivista-sistémico.

\section{Desarrollo}

\section{De objetos a sistemas y del modernismo al posmodernismo}

Desde la Antigüedad clásica los filósofos se han ocupado con la pregunta sobre la relación entre el mundo objetivo o la cosa en sí (el ser) y el conocimiento subjetivo que tenemos de este (la conciencia). Uno de los pensadores que precursaron la época moderna fue sin 
duda Descartes (Jaspers, 1937), a saber, a través de la separación clara entre el mundo material y el mundo psíquico o mental. Ese dualismo va a determinar no solo la división entre las ciencias naturales y las sociales, respectivamente humanistas, sino también nuestra manera habitual de pensar sobre la relación de la realidad física o natural con nuestro conocimiento de ella.

Descartes construyó un mundo dual, en el que existían en forma paralela dos regiones completamente diferentes: la mental (res cogitans) y la material (res extensa). Según él, la característica principal de la mente es el pensamiento, respectivamente sus expresiones, en la forma de sentimientos, voluntad, deseos, imaginaciones, valoraciones y juicios (afirmaciones y negaciones). Por otro lado, Descartes veía como característica del cuerpo humano su extensión y sus expresiones fenomenológicas físicas, tales como su posición, su forma, su movimiento, su tamaño, etc. El fundamento del modelo cartesiano no es otra cosa, entonces, que el supuesto de la existencia de ideas o categorías a priori (preestablecidas) y a través de las cuales la realidad física puede ser descrita y explicada. Ya que dichas ideas son innatas e independientes del sujeto no necesitan ni pueden ser cuestionadas. Según Descartes, estas categorías están constituidas por los principios lógicos fundamentales, por los conceptos de causa, extensión, cantidad, sustancia (la cosa, el asunto, el objeto), pero, sobre todo, por la idea de Dios.

Descartes parte, entonces, de un estado estático del mundo (estructurado por leyes mecánicas), el cual se origina de la creación divina. Sobre esa piedra angular se basa toda aquella actividad científica que se ocupa de las preguntas ontológicas, es decir, de cómo está formada la realidad que nos fue dada. Por otro lado, la pregunta del desarrollo de dicha realidad, a saber, la ontogénesis, no se plantea, debido al postulado de la creación del ser a través de Dios. En este sentido, Descartes solo acepta como verdadero aquello que refleja en forma clara y segura la esencia de un determinado objeto. Él duda siempre de la percepción sensorial, la que no debe ser tomada como real; por el contrario, en lo único que el sujeto investigador no deberá dudar es en sí mismo, ya que para poder dudar, primero, hay que existir (ser). La característica autorreferencial de su pensamiento le da al hombre la seguridad de ser real: cogito ergo sum (pienso, luego existo). Esta conceptualización del mundo implica una realidad estática, creada por un ser (Dios) que existe fuera de ella. Por otro lado, el hombre, también como un ser separado de esta realidad, tiene la tarea de entender dicha realidad en su esencia o características esenciales (leyes universales). En este mundo físico dado, las causas y los efectos están íntimamente unidos en forma lineal, de tal manera que las causas determinan los efectos.

La mente que aspira a conocer este mundo mecánico está fuera de él y sus observaciones no tienen -según este modelo- ninguna influencia sobre los procesos materiales observados. Las reglas del mundo físico externo se corresponden con las reglas de la razón, las que existen a lo interno de la mente del sujeto cognoscente. La verdad solo puede ser 
encontrada si es que se actúa de acuerdo con estas reglas y el conocimiento ganado así vendría entonces a ser un reflejo de la realidad estudiada. El ideal del conocer cartesiano es "la objetividad", es decir que observadores diferentes, estudiando el mismo fenómeno, deberán llegar a los mismos resultados, debido a que sus conocimientos están determinados por las características observadas en el objeto y no del proceso de observación o de las características del observador. Este enfoque cartesiano de carácter reduccionista ha sido la base del desarrollo científico de la modernidad desde la época de la Ilustración. En muchas disciplinas científicas, dicho modelo fue -y todavía lo es- exitoso; sin embargo, se basa sobre presupuestos que impiden comprender la complejidad del mundo posmoderno, sobre todo de aquel basado en sistemas organísmicos, psíquicos y sociales.

Empezamos con Descartes, ya que pensamos que es el pensador que más ha influenciado el pensamiento modernista. Él representa la tradición del pensamiento europeo antiguo, ya que sus postulados se basan en la filosofía platónica, pero, sobre todo, en la lógica aristotélica (Jaspers, 1937). Como racional, solo se aceptan aquellas argumentaciones y conclusiones que siguen las reglas de una lógica basada en la polaridad. Según esta lógica, los postulados son o verdaderos o falsos y una tercera posibilidad no existe (tertium non datur). Sin embargo, el observador está confrontado con una tercera posibilidad, si es que se permite la autorreferencialidad de los postulados. Por ejemplo, si un científico llega a la conclusión: “Todas las personas mienten”, quiere decir que él también miente, o si alguien me ordena: "Sé espontáneo", si sigo la orden no soy espontáneo y si no la sigo lo soy. Los postulados pueden ser entonces paradójicos, es decir que a través de las contradicciones se demuestran los límites de la lógica racional, ya que las afirmaciones paradójicas son siempre verdaderas, cuando son falsas y falsas cuando son verdaderas. Para evitar las paradojas, la separación entre sujeto y objeto es naturalmente una solución o método práctico para estudiar al mundo, pero nos limita fuertemente en su comprensión.

A partir de lo expuesto en el párrafo anterior, se hace necesario buscar modelos alternativos que expliquen el surgimiento de nuevas estructuras de regulación o control. La teoría de sistemas (Bateson, 1967, 1971, 1979; Bertalanffy, 1968; Luhmann, 1984, 1988, 1997) y el constructivismo (Maturana y Varela, 1970, 1984; Von Foerster, 1973, 1974, 1984,1988; Von Glasersfeld, 1985), que forman la base de lo que hoy se conoce como pensamiento sistémico, nos podría dar algunas respuestas a este respecto. La teoría de sistemas se ocupa del mundo de los objetos, pero no en forma aislada, sino con los fenómenos que resultan de las conexiones que forman entre ellos. El constructivismo, por su parte, se ocupa del conocimiento, el pensamiento y los procesos de valoración humanos, pero sin verlos separados del mundo que se pretende conocer, sino como parte de él; es decir, orienta su mirada a la interacción circular entre sujeto y objeto del conocimiento.

En el enfoque sistémico, el concepto de causalidad se redefine, es decir, en lugar de explicaciones causales lineales, aparecen explicaciones circulares o de retroalimentación. 
De esta manera, todo comportamiento de un sistema afectará el desarrollo de sus comportamientos posteriores, esto es así en la medida en que el sistema mismo se autocorrige a través de equilibrar disturbios y desviaciones que se apartan del valor ideal o establecido (por ejemplo normas) por medio del cual se autoorganiza o dirige. En este sentido, podemos hablar de la propiedad de autorreferencialidad de un sistema, ya que dichas normas autorreguladoras son desarrolladas por los mismos miembros que se someten a ella. El interés epistemológico del enfoque sistémico se traslada, entonces, de las cosas u objetos aislados y sus características hacia las pautas o los esquemas relacionales que dirigen las interacciones funcionales entre los miembros de un sistema, así como hacia las normas emergentes correspondientes que surgen de dichas interacciones. Los objetos de estudio serán ahora las estructuras y funciones de un sistema dado, es decir, las relaciones y posiciones que construyen entre ellos sus elementos, las reglas y normas que surgen de sus interacciones y comunicaciones, así como las regularidades que le permiten conservar o cambiar sus estados y estructuras internas, visto todo esto como totalidad. Los sistemas sociales producen los elementos que se encargan de construirlos.

El enfoque sistémico expuesto y su principio de autoorganización son compatibles con la aspiración de la ciencia moderna de hacer observaciones y explicaciones objetivas acerca del objeto estudiado; es decir, estas deberán ser independientes del observador y de las condiciones que lo rodean. En otras palabras, se cree en la neutralidad del observador al operacionalizar el lenguaje que usa para describir sus observaciones y en la independencia de las características del objeto de un ambiente determinado al intentar aislarlo durante la observación. En este nuevo caso, en lugar de investigar las características de los "objetos en sí”, se pretende hacerlo con las características de los “sistemas en sí”. Sin embargo, la abstracción o separación del observador del proceso de observación se hace difícil, si es que uno se confronta con la pregunta acerca de la biología del conocimiento. En este caso, se termina aterrizando tarde o temprano en la pregunta sobre la interrelación que existe entre el sistema observado y aquel que busca investigarlo; en otras palabras, del suprasistema que se forma entre observador y sistema observado. De esta manera, ambos forman, desde la perspectiva de otro observador, un sistema interactivo propio, que desarrolla sus propios procesos autorregulativos y que se autoestructura en el transcurso de su historia interactiva.

A través de la inclusión del investigador como parte del sistema observado, el enfoque sistémico se convierte ahora en epistemología, es decir, en ciencia del conocimiento. En este sentido, se deberán reformular las viejas preguntas filosóficas cartesianas: si los conceptos con cuya ayuda intentamos comprender y conocer el mundo ya no pueden ser vistos como ideas a priori, ¿de dónde vienen entonces? ¿De qué están constituidos los fundamentos de las ideas, las ideologías o las normas? ¿Cómo se desarrollan como estructuras? Todas esas preguntas, con las cuales se ocupa una rama de la psicología, respectivamente de la 
filosofía, es el objeto de estudio del constructivismo. La mayoría de los postulados constructivistas provienen de la investigación del desarrollo cognitivo en niños realizado por Jean Piaget (1928, 1930, 1964a, 1970b, 1975a, 1975b, 1975c, 1978, 1979a, 198ob, 1981, 1983). En un incontable número de estudios, Piaget no solo documentó y describió cómo surge la construcción de la percepción del mundo por parte de los niños, sino también describió su lógica inherente. Piaget nombró a su objeto de estudio epistemología estructural-genética.

En la medida en que los Estados y los organismos internacionales pretenden organizar y gobernar sus contextos (estructuras) internas y externas, de la misma manera necesitarán modelos cognitivos que les ayuden a explicar cómo se producen o tienen lugar los cambios que impulsarán el desarrollo deseado y así crear estructuras o normas de regulación adecuadas. Si un determinado comportamiento es valorado de manera negativa, de manera correspondiente se tratará de normarlo de manera diferente. Si, en cambio, se quiere alcanzar una meta determinada, se necesitarán para esto ideas y normativas que ayuden a su realización. En ambos casos, los actores construyen de manera hipotética mecanismos generadores de cambios y desarrollan para esto las normativas correspondientes; es decir, esquemas de acción, a través de los cuales se deberán organizar de manera dirigida los procesos o procedimientos necesarios para su realización. Una de las causas del porqué decidimos utilizar el enfoque constructivista o epistemológico de Piaget, radica en que los modelos racionales o lógicos a menudo no solo no llevan a la realización de lo planeado, sino que al mismo tiempo conducen también a efectos paradójicos. En este caso, se hace necesario entonces la utilización de un modelo que supere el dualismo cartesiano y esté más de acuerdo con las características autoorganizacionales y cooperacionales de los organismos sociales posmodernos.

\section{De un desarrollo determinista hacia uno constructivista: la epistemología estructural-genética}

Para explicar el origen del conocimiento, se han utilizado tradicionalmente dos tipos de explicaciones opuestas: la empirista y la apriorista o innatista. Para Aristóteles (Wiesner, 1987), todo conocimiento nace de la experiencia sensible, es decir, de la experiencia que obtenemos a través de los sentidos y del contacto directo con la realidad. Para Platón (Stenzel, 1931), en cambio, surgen primero las ideas y luego, de estas, los objetos del mundo sensible. Según el empirismo, el conocimiento proviene, entonces, de fuera del organismo humano y el sujeto aprende a recibirlo más o menos en forma pasiva; según la segunda, el fenómeno del conocimiento vendría a ser una imposición de las ideas (estructuras epistemológicas internas del sujeto) sobre los objetos.

En el siglo XX, el empirismo toma la forma del neopositivismo lógico (Russell, 1931; Wittgenstein, 1958); y el apriorismo, la forma de la fenomenología (Husserl, 1950) o del racionalismo crítico (Popper, 1935). Al empirismo, Piaget (1973) lo ha llamado 
"génesis sin estructuras" (evolución sin ideas) y al apriorismo "estructuras sin génesis" (ideas sin evolución). Frente a estas dos soluciones históricas, Piaget sostiene la postura propia $^{2}$ de que no existen estructuras epistémicas que no provengan de otras estructuras epistémicas, es decir, sin génesis, y de que toda génesis o evolución requiere una adaptación o acomodación de las estructuras epistémicas a su entorno. A su entender, el origen del conocimiento (estructuras epistémicas) no se explica suficientemente ni a partir solo del objeto (estructuras normativas externas) ni solo del sujeto (agente o estructuras normativas internas), constituidos, y vistos ambos de forma independiente el uno del otro. Según Piaget, tanto el sujeto como el objeto del conocimiento vendrían a constituirse a través de la interacción adaptativa que ocurre entre ambos y la cual es la base de la realidad que conocemos.

Desde la perspectiva piagetiana, el concepto de conocimiento obtiene entonces un nuevo significado, es decir, no refleja solo procesos psíquicos, sino que abarca todas las formas estructurales de los organismos vivos y su objetivo funcional será garantizar la supervivencia de estos. El postulado anterior vendría a significar que todos los sistemas organísmicos (que incluyen los sociales) son sistemas epistémicos (cognitivos) y la vida no sería otra cosa que un constante proceso de equilibración epistémico entre el organismo y su contexto de referencia. Según este enfoque, los organismos transforman sus estructuras y funciones en el transcurso de la evolución, de tal manera que sean capaces de adaptar su comportamiento a las condiciones dadas y así sobrevivir. Dentro de esas estructuras biológicas y pautas funcionales están implicados los conocimientos que el organismo posee sobre el contexto correspondiente. A través de sus actividades, los organismos describen o reflejan la realidad que perciben, es decir, el contexto interactivo a través del cual son capaces de conservar su organización interna y externa (equilibrio interno y externo). La calidad de los conocimientos de un organismo se mide, entonces, a través de su capacidad de aumentar sus posibilidades de supervivencia.

La idea fundamental de la epistemología genética consiste, entonces, en que el conocimiento no es otra cosa que un fenómeno adaptativo, el cual surge genéticamente de la relación en constante desarrollo que tiene lugar entre el organismo humano (sociedad) y su contexto de referencia (naturaleza) (Piaget, 1971b). En ese intercambio dialéctico, consiste exactamente el proceso adaptativo biológico, que, en el aspecto social y mental, no es otra cosa que el desarrollo progresivo de la organización social humana (operaciones normadoras de la actividad social). El conocimiento vendría a manifestarse, según esta teoría, en forma de una sucesión de estructuras epistémicas llamadas estadios operacionales, los cuales se desprenden unos de otros (Piaget, 1971a). De esta

2 Piaget se apoyó ante todo en el operacionalismo de Percy Bridgmans, así como en la teoría neokantiana del conocimiento de Paul Natorp. 
manera, la epistemología genética, vista desde su forma neoconstructivista (Pastrana y Gehring, 2014), busca descubrir las raíces de los distintos tipos de conocimiento o normas interaccionales, desde sus formas más elementales hasta los niveles superiores, que incluyen las operaciones instrumentales (sensorio-motrices), las operaciones motivacionales (preoperacionales), las operaciones estratégicas (operaciones concretas), operaciones morales (preformales), las operaciones institucionales (formales) y las operaciones sistémicas (posformales); estas últimas operaciones representan el estadio constructivista-sistémico y que no fue estudiado por Piaget.

$\mathrm{Al}$ proceso de adaptación mutua entre la realidad (entorno sistémico) y las normas construidas por el organismo social para interactuar con ella, se le denomina "proceso de equilibración" (es decir, dicha interacción aspira a un equilibrio o síntesis entre ambas estructuras) (Piaget, 1972, 1976). Los conocimientos construidos, para Piaget, siempre son el resultado del proceso de adaptación. El punto de partida de toda adaptación es el surgimiento continuo de contradicciones (perturbaciones paradójicas) entre la experiencia actual con el entorno y los esquemas reguladores existentes sobre él (desequilibrio). Estas contradicciones solo pueden ser solucionadas a través de una acomodación organísmica -adaptación activa y autoorganizada del sistema de sus estructuras internas-durante el proceso interactivo con su entorno. El proceso epistemológico se reduce, entonces, a la pregunta de cómo el organismo social puede aumentar su capacidad de conocer y regular, en forma más adecuada, su entorno o realidad sistémica, con la cual está conectado constitutivamente; es decir, de la cuestión del desarrollo de la capacidad de adaptarse y sobrevivir. Esta capacidad radica en la construcción sistemática y escalonada de nuevas estructuras o normas de acción, las que vendrían a garantizar el acercamiento progresivo a un conocimiento práctico o efectivo del entorno que el organismo quiere o necesita conocer.

\section{Conceptos clave del constructivismo piagetiano}

\section{Asimilación-acomodación}

El desarrollo adaptativo de supervivencia de los seres vivos refleja un proceso paradójico de tener que transformar las estructuras organísmicas sin pérdida de la propia organización; es decir, de conservación de identidad. De esta manera, existen en el organismo en evolución partes que permanecen invariables y otras que se transforman. Entre las partes variables, encontramos aquellas que se desarrollan en forma sistemática y otras que cambian dependiendo del estado interno especial del organismo, así como de las circunstancias particulares de su entorno en un momento dado. Los elementos variables están representados por las estructuras epistémicas internas del organismo y por las estructuras sistémicas que conforman el entorno. Las partes invariables, por otro lado, están representadas ante todo por la organización organísmica representada por sus funciones 
adaptativas con carácter equilibrador (garantizan la homeostasis organísmica). Los mecanismos funcionales que utiliza el organismo para transformar tanto las estructuras epistémicas externas como sus estructuras internas son la asimilación y la acomodación. Asimilación es la acción transformadora del organismo sobre los objetos o sistemas del entorno con los que interactúa, mientras que la acomodación representa la transformación de sus propias estructuras, a fin de equilibrarse con su entorno sistémico (Piaget, 1976).

Toda interacción entre organismo y entorno ocurre a través de acciones concretas del organismo. El organismo solo podrá conocer su entorno en la medida en que trate de asimilarlo (controlarlo). Un bebé conoce el pecho materno solo succionándolo y un escritor solo aprende a escribir escribiendo historias. La tendencia del organismo de asimilar su entorno y de conservar su organización es constitutiva de este. Sin embargo, tales intentos encuentran siempre un menor o mayor grado de resistencia por parte del entorno, ya que este se encuentra en constante cambio, lo cual provoca la activación de la acomodación. Piaget remarca el carácter circular de ambas funciones y de que, prácticamente, siempre aparecen juntas, aunque con distinto peso dentro de las fases del proceso interactivo. A este proceso circular de desarrollo, Piaget lo dividió en tres fases interactivas circulares: 1) Un organismo o sistema organizado fracasa al tratar de asimilar un determinado objeto del entorno, lo cual lo obliga a realizar variaciones en su comportamiento. 2) Los comportamientos exitosos van a tender a ser repetidos y los no exitosos a ser catalogados como "errores", es decir, tiene lugar un proceso de selección. 3) A continuación, y a fin de poder retener los comportamientos exitosos y convertirlos es esquemas, el organismo tendrá que repetirlos constantemente. Al tratar de implementarlos, el organismo se topará de nuevo con otras dificultades, y así el círculo comienza de nuevo. La fase de variación es acomodación, la de repetición es asimilación y la de selección también, pero ya menos. A través de las actividades organísmicas se desarrollan, en él, esquemas de acción o conocimientos (habilidades, hábitos, estrategias, normas, etc.) que deberán permitirle controlar su entorno, es decir, sobrevivir.

\section{De la acción al lenguaje: lucha por el control del entorno}

Según Piaget (1975b, 1975c), la unidad epistémica a través de la cual un organismo ordena sus interacciones tanto internas como externas se llama esquema cognitivo. Un esquema cognitivo no es otra cosa que una norma, ya que ambos conceptos representan la forma típica o estándar de manejar o interactuar con un determinado evento. En otras palabras, ambas categorías reflejan aquel conjunto de elementos que es común a la repetición o realización de una misma acción o conducta. En este sentido, las normas -al igual que los esquemas- nos ayudan a simplificar las interacciones con el entorno (reducción de complejidad), debido a que utilizan las mismas estrategias para enfrentar diferentes situaciones; es decir, promueven invariancia. En este sentido, los esquemas 
normativos son selectivos e interpretativos, es decir, deforman y determinan la forma de percibir el entorno. Los organismos sociales desarrollan y transforman sus esquemas normativos internos durante la interacción acomodadora que sostienen con los sistemas que conforman su contexto. Dichas normas se autoorganizan -estimuladas pero no determinadas- a través de estas interacciones (o tal vez no, si es que estas normas o conocimientos son confirmadas en la interacción, es decir, si la asimilación funciona). Estos esquemas cognitivos o normas es aquello a lo que llamamos conocimiento (la repetición de procesos operacionalizados o pautas procesuales).

Por otro lado, las estructuras epistémicas vendrían a ser redes organizadas de normas. Con una sola norma, un organismo cualquiera no puede regular u ordenar mucho, y con una cantidad de normas desconectadas entre ellas, mucho menos. Solo a partir de una vinculación ordenada y coordinada de todas las normas, el organismo estará en capacidad de garantizar una regulación y un ordenamiento interno y externo efectivos. La construcción de diferentes normas (implícitas o explícitas) y su respectiva coordinación en estructuras es la característica principal que refleja el desarrollo de los organismos vivos. Esto es válido también para las actividades mentales (la inteligencia, para Piaget, al igual que el instinto, no es más que una extensión estructural adaptativa del organismo mediante la cual regula sus interacciones con el medio). El concepto de operación es usado por Piaget como sinónimo de pensamiento, ya que para él este último representa en esencia más bien una actividad u operación concreta, la cual fue interiorizada por un sujeto interactuante. A diferencia de la actividad concreta, que se manifiesta en los actos cognitivos con carácter sensorio-motriz y realizados directamente a través de la interacción con la realidad externa, el pensamiento representa, por el contrario, una actividad u operación interiorizada. La interiorización provoca, sin embargo, la sustitución del objeto en particular por su forma simbolizada (Piaget, 1971b, 1975a).

La primera clase de esquemas normativos de la actividad, a través de los cuales el organismo representa y controla su entorno, se compone de la coordinación de esquemas motrices y esquemas sensorios, es decir, de estructuras sensorio-motrices (Piaget, 1971a). Estas actividades son de carácter instrumental y están dirigidas a la interacción directa con el entorno físico. La primera fase de interiorización radica en convertir las estructuras sensorio-motrices en representaciones o acciones mentales llamadas estructuras ideoperceptivas. Estas representaciones normativas no son copias de una realidad preformada y más bien representan esquemas que nos ayudan a percibir los estímulos externos y darles un carácter simbólico. El individuo depende ahora de una percepción determinada por normas ideoperceptivas. Esta interiorización le permite al ser humano una relativa emancipación y control de la acción real. Aquí se imitan interacciones reales a través de rituales mágicos y se aspira así a tener control sobre los eventos del entorno, surgen rituales para hacer llover, para tener éxito en la caza de animales, para vencer enfermedades, 
etc. Las actividades de estas estructuras son de carácter intersubjetivo y cooperativo. La independencia de los esquemas normativos de los eventos externos concretos alcanza un nuevo nivel cualitativo a través de una segunda fase de interiorización; a saber, cuando las representaciones simbólicas concretas se transforman ahora en estructuras operacionales, es decir, en actividades internas abstractas de carácter variable. Estas actividades ahora son de carácter autoorganizacional, lo que vendría a independizar el organismo de su entorno de forma todavía más acentuada. De esta manera, surge una nueva estructura normativa con características formales: el lenguaje (Piaget, 1962, 1979a, 1980b).

El lenguaje está formado, entonces, por representaciones mentales de la realidad que pretendemos conocer. Estas representaciones surgen a través de la elaboración de símbolos que desarrollan los actores sobre las experiencias hechas con dicha realidad. De esta manera, la función semiótica (simbólica) ofrece al actor, ya sea en el lenguaje abstracto, en forma de signos o letras, o en las imágenes concretas, como símbolos que se parecen al objeto que representan, un medio de ayuda para representar aquello que él ya conoce, pero también para interactuar con otros actores sociales. En esta función mediadora e interactiva, las representaciones simbólicas de la realidad son indispensables, ya sea para manipular, para usar en forma más flexible, para conservar y también para renovar el conocimiento colectivo (normas o ideas) del que dispone cada actor social; es decir, en la administración, disponibilidad y transformación de los conocimientos adquiridos por este.

La función semiótica tiene su origen en la imitación y es, en su esencia, una internalización de la imitación que el actor hace de actividades externas (interactividad) (Piaget, 1975c). El concepto de internalización describe, sin embargo, dos funciones diferentes en la semiótica. Por un lado, "interiorizar" como disociación funcional entre esquemas cognitivos generales (normas e ideas) y contenidos externos (objetos y sistemas); y por otro, "internalizar" como desaparición de las actividades de imitación del actor y su transformación en representaciones concretas (imágenes simbólicas) o abstractas (lenguaje o signos). A través de ambas funciones, los actores adquieren o creen adquirir más influencia y control sobre su entorno, hecho que les permite aumentar su confianza en sus interacciones con él.

Con relación a los aspectos simbólico (interactivo) y operativo (interno) del lenguaje (y por ende la comunicación entre actores), existen dos fuentes de las que él se nutre: por un lado - como ocurre también con la percepción-, el aspecto simbólico se desprende de las actividades acomodadoras del actor (interactivas); por el otro, sus representaciones internas reciben una significación a través de apoyarse en el acto cognitivo-operativo e institucional de los actores; es decir, de sus esquemas o ideas normativas (actividad asimiladora). Basada en este supuesto, una representación simbólica o normativa surge, entonces, en la medida en que los elementos simbólicos internalizados (experiencias) conformen, por un lado, el material de construcción, los cuales, por otro lado, recibirán su significación normativa solo después de asociarse con una norma o idea anterior. 
La representación simbólica refleja así el "significado", mientras que la norma o idea anterior vendría a fungir como "significante".

\section{Reversibilidad y equilibración}

En cada uno de los niveles de representación cognitiva mencionados, los esquemas se autoorganizan (coordinan) en estructuras epistémicas (sistemas cognitivos). Es en esta coordinación diferenciada que consiste el desarrollo de cada estadio cognitivo (sensoriomotriz, concreto y formal), ya que dicha estructuración grupal de esquemas o normas permite una gran flexibilidad de acción, las acciones mentales se pueden retroceder, los mismos objetivos pueden ser alcanzados por distintos caminos, etc. Piaget (1976) nombra a estas ventajas operacionales "reversibilidad" y al estado coordinado de los esquemas que se alcanza a través de la autoorganización (asimilación y acomodación internas) “equilibrio”. Los esquemas o normas que no están integrados en estructuras o sistemas epistémicos realizan “acciones”; si están integrados, sus actividades se llaman “operaciones” y denotan actividades internas de autorregulación.

En relación con lo dicho, el desarrollo aspira a la construcción de equilibrios. Piaget diferenció tres tipos de equilibrios interactivos:

1. El equilibrio entre organismo y entorno (o entre asimilación y acomodación).

2. El equilibrio entre diferentes normas o esquemas, en general, entre subsistemas normativos.

3. El equilibrio entre un esquema (norma) y una estructura (normativa), en general, entre subsistemas y el metasistema.

Un ejemplo de un desequilibrio del primer tipo es cuando alguien quiere levantar un objeto que es más pesado de lo que él espera (el esquema activado no puede asimilar el objeto); un ejemplo de desequilibrio del segundo tipo es cuando alguien quiere usar el mismo objeto como bola de tenis de mesa y como instrumento para abrir una nuez; y un ejemplo de equilibrio del tercer tipo es cuando alguien marcha hacia atrás en busca del vagón restaurante en un tren, sabiendo, sin embargo, que el tren se mueve hacia delante. Los desequilibrios aparecen ya sea por la resistencia que opone el objeto o sistema a ser asimilado o a través de conocimientos insuficientes, experimentados como expectativas normativas que no se cumplen.

Las perturbaciones causantes de desequilibrios van a tratar de ser compensadas. Piaget (1975d) diferenció dos tipos de compensación, a saber, la desaparición de la perturbación a través de su inversión o negación (por ejemplo un niño que sube a un árbol deberá aprender a bajarse de él) o la diferenciación de los esquemas normativos de acción (construcción de reciprocidad entre esquema y objeto). La reproducción 
de un equilibrio perdido lleva a una diferenciación de los esquemas y con esto a una nueva síntesis estructural, por lo que Piaget (1976) nombró las equilibraciones que representan pasos en el desarrollo “equilibración mayor”. Piaget remarcó que todos los equilibrios tienen un carácter temporal, no solo porque la realidad objetual o sistémica se encuentra siempre en constante cambio, sino porque el organismo no es capaz de integrar todas las informaciones que necesita y así tendrá siempre que completar este vacío epistémico.

\section{Diferenciación e integración}

A partir de lo expresado en los párrafos anteriores, podemos caracterizar las transformaciones que ocurren durante el desarrollo de normas como procesos de "diferenciación" e “integración”, así como de "descentralización”(Piaget, 1971a). El organismo social adquiere cada vez más esquemas normativos, es decir, diferencia más durante sus acciones de intercambio con su entorno, al mismo tiempo, dichas normativas son coordinadas o integradas más adecuadamente en estructuras epistémicas nuevas o actualizadas. De esta manera, el organismo percibe y regula en forma más diferenciada su entorno, pero esa diferenciación no es caótica, debido a las nuevas conexiones internas. Nuestra percepción trabaja solo con diferencias y cada información o conocimiento que obtenemos del entorno representa necesariamente una ampliación de las diferencias que percibimos de un determinado evento o estado de cosas en nuestro entorno. Naturalmente, estas diferencias no representan las características objetivas de lo observado, sino más bien instrumentos (hipótesis) que el organismo social construye para entender mejor a -respectivamente interactuar mejor con-su entorno.

En la construcción de diferencias a nivel social, el lenguaje desempeña un papel muy importante, no solo porque nos ayuda a reflexionar sobre nuestras propias experiencias (nivel psíquico), sino porque como medio donde ocurre la comunicación social nos abre la posibilidad de conocer los procesos internos de las otras personas u organismos sociales con los que interactuamos (Luhmann, 1988). En este sentido, se diferencian tres niveles del proceso de diferenciación y de integración: la “descripción” (implica la selección de los fenómenos que se observan), la "explicación” (cuáles hipótesis y conexiones se plantean) y la "valoración" (interpretación de su significación para el organismo) del fenómeno que se intenta conocer. Esos tres aspectos de la construcción de una diferenciación están íntimamente relacionados, es decir que en la práctica no se pueden realmente separar. Por ejemplo, cuando construimos una explicación sobre algo que hemos percibido, automáticamente su valoración también cambia, más concretamente, si explicamos el comportamiento criminal de alguien como consecuencia de una enfermedad, tendrá naturalmente otra significación que si lo interpretáramos como un acto de maldad o de crueldad. De esta manera, ya no será un malhechor sino 
víctima de un mal interno (dependiendo del nivel sociocognitivo del agente normador que valora: una fechoría, un castigo divino, un embrujo o una enfermedad).

\section{Objetivación, descentralización y reconstrucción aproximativa}

La objetividad, en sentido piagetiano, no está basada en el conocer los contenidos de un objeto o entorno estático, sino más bien en observarla como un proceso interactivo entre un organismo y un entorno que se influencian mutuamente y los cuales se encuentran en constante cambio. En otras palabras, se puede hablar de objetividad (Von Glasersfeld, 1985, prefiere hablar de viabilidad), pero si la vemos como reflejo de la interacción constitutiva entre el organismo social y una realidad sistémica en constante transformación. Para explicar la acomodación o proceso de acercamiento a la realidad objetual (ahora sistemas), Piaget (1983b) utiliza los conceptos complementarios de diferenciación e integración. La objetividad o capacidad viable de supervivencia que posee la representación de la realidad de cada organismo social - al igual que los esquemas o normas que la sustentan- está sujeta a transformaciones, las cuales pueden ser investigadas durante el desarrollo cognoscitivo del organismo social estudiado. Objetividad vendría a ser en este sentido - según Piaget- “un proceso y no un estado”. Vista como supervivencia pragmática de un organismo social en especial (por ejemplo un Estado), la objetividad de la realidad compartida por varios organismos deviene una objetividad relativa, pluralista y sistémica. Este proceso de objetivación o acomodación está regulado por dos mecanismos complementarios, a saber, "la descentralización” y la "reconstrucción aproximativa". Esos mecanismos trabajan siempre juntos, sin embargo, se pueden presentar teóricamente en forma separada.

Según Piaget (1970a), solo podemos conocer el mundo si interactuamos activamente con él, es decir, si tratamos de asimilarlo o de cambiarlo. Este supuesto implica que la base de todo conocimiento radica en la participación activa del sujeto del conocimiento. En este sentido, cuando hablamos de objetividad, no estamos tratando de saber si el sujeto participa en el surgimiento o construcción de los conocimientos, sino en qué medida esa participación deforma el objeto que está buscando conocer. Dentro de este contexto interactivo, la polaridad conceptual "centralización-descentralización" viene a ganar una significación determinante en el desarrollo del conocimiento colectivo.

Centralización. Centralización significa que un actor dispone siempre solo de medios limitados para interactuar con el mundo y conocerlo (estructuras sociocognitivas en desarrollo). La percepción unidireccional de un objeto, por parte de un sujeto, sobre la base del nivel actual de desarrollo de las estructuras cognitivas de este, es llamada por Piaget “egocentrismo” y más tarde “centralización”. En la centralización, el mundo es entonces asimilado por el actor en cuestión, es decir que este deforma y adapta la 
percepción que hace del mundo en relación con el nivel de desarrollo de sus estructuras sociocognitivas y normativas (institucionales) actuales.

La “centralización” representa así, por un lado, la dominación o primacía subjetiva de los observadores normativos -y de la satisfacción de sus necesidades de autoconservación-sobre la posible percepción objetiva de lo observado; por otro lado, se trata también de una deformación de la realidad objetual o sistémica (entorno) en función de la intención asimiladora del agente normador durante la acción, así como su punto de vista acerca del porqué la realiza (sentido: explicación y valoración). En ambos casos, el proceso de centralización ocurre de forma inconsciente para el observador específico, debido a que al centralizar este no diferencia entre él $-\mathrm{y}$ por ende sus intereses $-\mathrm{y}$ la posición de objeto de su entorno; es decir que subjetividad y objetividad están entremezcladas en su actividad del conocer.

Descentralización. Por el contrario, el "proceso de descentralización” (observación de la observación) define la capacidad creciente de un observador determinado -la que va adquiriendo en el transcurso de su desarrollo- de poder tomar el punto de vista de otros observadores o de colocar su percepción desde la posición del objeto o sistema que pretende conocer. El proceso de descentralización busca entonces superar la centralización, en la que está atrapado todo observador normativo, a saber, a través de la activación y el fortalecimiento del mecanismo de la acomodación, es decir, de liberar al observador del hecho de estar atrapado en su propia subjetividad inconsciente.

El proceso de descentralización u objetivación es al mismo tiempo rectilíneo y cíclico, es decir, ocurre en forma de espiral (nivel más alto de desarrollo). Al comienzo de un nuevo estadio o equilibrio del desarrollo sociocognitivo, ocurre siempre una centralización (identificación con las nuevas estructuras), la cual va cediendo en consistencia al aproximarse el final de dicho estadio; esta transformación se produce en favor de una tendencia descentralizadora. La nueva tendencia parte siempre del objeto (contexto político externo) hacia el actor político e implica la toma de conciencia de este, de su participación inconsciente, subjetiva y deformadora, en el surgimiento y la construcción de la meta y el sentido de la actividad que realizaba. Esta toma de conciencia implica, entonces, que la identidad (descripción, explicación y valoración que hace el actor de él mismo) que el actor tenía, y que le era imposible percibir, ahora se ha convertido en objeto de su estudio; es decir, el actor recibe la oportunidad de conocerse más diferenciadamente a sí mismo, o dicho en otras palabras, el conocimiento se conoce a sí mismo (principio de circularidad). Esto significa que, aunque en cada nuevo estadio sociocognitivo del desarrollo el ciclo empieza de nuevo (se repite), este alcanza, sin embargo, un nivel superior, visto desde la posición del sujeto, es decir, muestra un progreso a través de la dinámica descentralizadora. Este proceso en espiral refleja una dinámica de un 
repetir sin repetir. En este desarrollo en espiral, se activan dos mecanismos opuestos: la "abstracción reflexiva” y la "equilibración” (Piaget, 1976).

La abstracción reflexiva. Por abstracción se entiende la capacidad del actor de separar (descentralizar) ciertos esquemas organizativos e integrarlos en otras estructuras de su identidad actual (recontextualización). La reflexión tiene dos significaciones: por un lado, define la proyección de una significación normativa en la que la estructura aislada es proyectada en otro nivel o escenario (contexto). Por otro lado, significa el sentido representativo de una elaboración o análisis mental en la que el sistema normativo completo, en la que se encuentra el esquema normativo, se integra en una estructura normativa (más compleja) de un estadio superior.

La abstracción reflexiva o reflexión abstracta sube así los conocimientos normativos (identidad) de un estadio sociocognitivo inferior a otro superior y le da a este una nueva forma y al mismo tiempo un nuevo significado normativo; este mecanismo contribuye tanto a la liberación de las normas de su estado de centralización como a su conservación (recontextualizándolas). Así tenemos que la recontextualización de las normativas de un actor estatal y de sus estructuras internas tiene consecuencias para la estructura normativa regional (totalidad). Los efectos resultantes que surgen en los otros actores pertenecientes a la región, así como de la interacción de esta con su entorno global, provocan un desequilibrio y una crisis de identidad en ella. En este estado de descoordinación, la región se verá entonces obligada a activar el mecanismo de equilibración. Un nuevo equilibrio estados-región-sistema global implica siempre la activación de las funciones de asimilación y acomodación, con el fin de manejar los procesos correspondientes de diferenciación, coordinación e integración, y así contribuir a la construcción de una nueva estructura general (identidad regional o global). A través del mecanismo de la equilibración, la región -y sus actores- se centraliza de nuevo, lo cual viene a fortalecer la asimilación y la integración cohesionada. El ciclo comienza otra vez.

Reconstrucción aproximativa. Otro mecanismo del proceso de objetivación (equilibración) es la "reconstrucción aproximativa" (Piaget, 1976). Este concepto describe el hecho de que mientras ocurre el proceso de descentralización tiene lugar al mismo tiempo una transformación de nuestra representación de la realidad. Esta transformación se fundamenta en el hecho de que los esquemas normativos de una región tienden a asimilarse mutuamente en forma recíproca. "Asimilación recíproca” significa aquí que una norma se subordina a otra o se deja subordinar por aquella (acomodación) y así se hace posible la coordinación normativa dentro de la estructura regional. Esto vendría a significar que la reconstrucción de la vieja representación de la realidad y de las viejas estructuras normativas (ideología e identidad) ocurre dentro de la estructura regional 
y obedece al principio de autoorganización, aun cuando los estímulos de cambio provengan del estado de desequilibrio que presenta una determinada región en relación con el desarrollo del sistema normativo mundial.

Este último hecho implica que la reconstrucción de los esquemas normativos dentro de la estructura regional no es una actividad voluntarista o independiente de la experiencia interactiva empírica de las regiones con su entorno; por el contrario, ocurre provocada por la contradicción que proviene de esta. El confrontamiento de una región con dicha contradicción genera un proceso de acomodación (cambio en las estructuras internas), que, a su vez, desencadena un proceso de selección interno entre los actores regionales con carácter competitivo. En la medida en que avanza este proceso de intentos de asimilación recíproca entre las normas interactuantes (proceso de selección), estas podrán acomodarse mejor - como estructura normativa regional- a las nuevas circunstancias mundiales. Es así como las nuevas construcciones normativas o identidades colectivas vienen a alcanzar un acercamiento más objetivo o viable con la realidad externa. Dicho en otras palabras, las estructuras normativas o construcciones reguladoras hipotéticas que surgen en forma sucesiva en la región en evolución intentan responder a las exigencias empíricas dadas de la manera más óptima. Durante el proceso de asimilación recíproca (selección) unas normativas y sus estructuras se tendrán que acomodar o serán asimiladas por aquellas que representan las propuestas estructurales que se acercan más a la realidad a la que la región tiene que acomodarse.

En general, si durante la equilibración las soluciones y los propósitos comunes son exitosos, el nivel de integración y cohesión regional aumentará. Por el contrario, si las acciones equilibradoras en común fracasan, esto disminuirá la integración y la disposición a la cooperación, lo cual de nuevo iniciará procesos de acomodación y diferenciación, es decir, competencia y confrontación internas, a fin de encontrar nuevas alternativas de acción.

\section{Una epistemología neoconstructivista}

El punto de partida de este enfoque es el desarrollo genético de las "estructuras sociocognitivas de normación" de la actividad humana, las que surgen de aquel proceso de adaptación recíproco general entre el agente humano y su entorno natural (proceso de equilibración). Visto el desarrollo así, tanto las normas como las estructuras en las que están enmarcadas, poseen un mismo origen (esquema circular primario), con lo que ambas solo estarían representando momentos y aspectos distintos de aquella estructura original. La circularidad que caracteriza el desarrollo normativo de la actividad social humana se basa, entonces, en el hecho de que todo nuevo conocimiento o teoría del conocimiento solo podrá emerger sobre la base de los viejos conocimientos (estructuras sociocognitivas). Como resultado de este 
principio circular de estructuración, las acciones normativas no son voluntaristas, y más bien están determinadas tanto por el nivel de desarrollo sociocognitivo (estadios) en que se enmarcan como por su propósito o intención con respecto al objeto o evento significativo que pretenden regular (asimilar).

La investigación sociogenética e histórica de las formas del desarrollo del conocimiento normativo (estructuras sociocognitivas) que emprendemos en este artículo tiene por lo menos dos posiciones de estudio, una centralizada y basada en el enfoque piagetiano de referencia y una descentralizada, la cual reconoce que no existen conocimientos fuera del acto del conocer, hecho que nos hace conscientes de nuestra subjetividad constitutiva y por ende nos obliga a estar abiertos a iniciar procesos de equilibración ante las contradicciones constantes que encontraremos en nuestras construcciones aproximativas (hipótesis normativas). La investigación sobre esquemas normativos que realizamos se enmarca así solo en dar respuesta a la pregunta de cuáles son y cómo surgen las estructuras sociocognitivas de normación, a saber, a partir de los postulados de la epistemología estructural-genética de Piaget (1971a) y de sus sucesores neoconstructivistas genéticos: Kohlberg (1958, 1963, 1969, 1973, 1976) y Kegan (1982, 1994), así como otros modelos estructurales que describen la evolución sociocognitiva del ser humano (Gebser, 1999; Bellah, 2011; Lenski, 1963; Fowler, 1991; Beck, 1975; Habermas 1976, 1985, 2001, 2005). La mayoría de estos modelos muestran isomorfismos con respecto a los estadios del desarrollo cognitivo piagetiano. Por ejemplo, si tomamos el modelo estructural de Habermas (1976, 2005), observamos las siguientes equivalencias (cuadro 1):

\section{Cuadro 1. Equivalencias del desarrollo estructural cognitivo de Piaget y social de Habermas}

\begin{tabular}{|l|l|}
\hline \multicolumn{1}{|c|}{ Piaget } & \multicolumn{1}{c|}{ Habermas } \\
\hline Estadio sensorio-motriz & Época arcaica y preconsciente \\
\hline Estadio preoperacional & Época mágica-animista (tribus étnicas) \\
\hline Estadio operacional concreto & Época mitológica \\
\hline Estadio de las operaciones formales & Época racional \\
\hline
\end{tabular}

Fuente: elaboración propia.

\section{Identidad organísmica}

Los organismos sociales al igual que los biológicos no solo organizan sus propias estructuras, sino que al mismo tiempo producen los elementos (esquemas normativos) de que estas se componen. Las estructuras normativas y sus elementos (esquemas normativos) 
se transforman sobre la base de las anteriores; sin embargo, los procesos organizativos que se encargan de reproducir los elementos y reconstruir las estructuras organísmicas permanecen estables. En otras palabras, la autoorganización organísmica -y con esta la identidad homeostática organísmica- está garantizada por las funciones interactivas de la asimilación y la acomodación.

El desarrollo sociocognitivo radica, entonces, en las diferenciaciones estructurales paulatinas que construye el organismo social para coordinarse con su entorno y así integrarse de nuevo en este con una nueva estructura normativa (identidad ampliada) -es decir equilibrarse- (diferenciación-integración). De esta forma, el organismo social recupera el control homeostático perdido (desequilibrio) y reconstruye, al mismo tiempo, sus fronteras con el exterior. Si en el transcurso de su desarrollo estructural el organismo social reflexiona o se observa a sí mismo, descubrirá por lo menos dos posiciones implícitas en dicha observación. Primero, se vivencia desde la posición de sujeto observador (posición centralizada); y segundo, describe, explica y valora una parte de sí mismo como objeto o sistema observado, con cuyas características se puede identificar o no (posición descentralizada). El observador centralizado (identidad sujeto) representa el estadio estructural normativo actual del organismo social, y el observador descentralizado (identidad objeto) refleja los estadios más o menos integrados en la autopercepción (identidad subjetiva) del mismo organismo. Solo podemos percibir y controlar aquellos estadios sociocognoscitivos de los que ya nos hemos descentralizado.

El modelo normativo estructural que presentamos en este artículo se basa en un desarrollo que muestra siempre un mismo principio dinámico: el organismo social busca activamente controlar (asimilar) su entorno, en la medida en que trata de diferenciarse e independizarse cada vez más de la estructura o sistema en el que se encuentra integrado (estadios de diferenciación o emancipación); sin embargo, en la medida en que dicho entorno se oponga a ser asimilado por el organismo - y provoca de esta manera un desequilibrio en la homeostasis organísmica- se activarán procesos de acomodación y por ende de cooperación o coordinación, que en última instancia obligan al organismo a reintegrarse de nuevo a su entorno de referencia (estadios de integración). Nuestro modelo neoconstructivista presenta una estructura vertical de seis estadios evolutivos, en los que la importancia de las actividades de diferenciación o de integración cambia en forma alternada con cada estadio. Este movimiento refleja una figura del desarrollo en forma de espiral, es decir que la repetición de cada dinámica (diferenciación o integración) tiene lugar a un nivel cualitativo superior. A continuación, presentaremos dichos estadios (cuadro 2). 
Cuadro 2. Analogía isomorfa entre los estadios del desarrollo cognitivo de Piaget (ampliados por los neoconstructivistas) y los estadios del modelo genético sociocognitivo del autor

\begin{tabular}{|l|l|}
\hline \multicolumn{1}{|c|}{ Estadios del desarrollo normativo } & $\begin{array}{c}\text { Función organizativa } \\
\text { (diferenciación frente a integración) }\end{array}$ \\
\hline Estadio instrumental (sensorio-motriz) & Diferenciación \\
\hline Estadio motivacional (preoperacional) & Integración \\
\hline Estadio estratégico (operacional concreto) & Diferenciación \\
\hline Estadio moral (preoperacional formal) & Integración \\
\hline Estadio institucional (operacional formal) & Diferenciación \\
\hline Estadio constructivista-sistémico (operacional dialéctico) & Integración \\
\hline
\end{tabular}

Fuente: elaboración propia.

Todas las estructuras normativas están entonces enmarcadas en estadios sociocognitivos del desarrollo humano, es decir, reflejan el equilibrio organismo-entorno alcanzado en un determinado momento del desarrollo de los organismos sociales. La identidad normativa de un organismo social, por otro lado, está representada por el conjunto de estructuras normativas que este utiliza (coordina), a fin de relacionarse con él mismo y con otros organismos o sistemas del entorno con carácter significativo para él. Por otro lado, la construcción de normas se deberá entender como un proceso circular e interactivo: los otros organismos sociales ganan para el organismo una determinada significación, pero también el organismo - a través de su desarrollo- gana importancia o desinterés (aislamiento) para los otros organismos. Dar y obtener significación son resultados concretos de la actividad interactiva de cada organismo. Este proceso de dar y recibir significación por parte de los organismos sociales está siempre determinado por las funciones reguladoras de la asimilación y la acomodación.

\section{Estadios sociocognitivos del desarrollo normativo}

El desarrollo normativo, como explicamos anteriormente, ocurre siempre a través de un proceso dialéctico y circular entre dos actividades opuestas: descentralizaciónrecentralización, es decir, a través de un cambio alternado de procesos de diferenciación (separación o emancipación del organismo social de su estructura de referencia) y de procesos de integración (reintegración del organismo social en un nivel cualitativo superior). Esta dinámica representa ante todo cambios de dirección en el desarrollo normativo (interno-externo) y donde los límites organísmicos se están reconstituyendo constantemente. Las etapas de transición entre estadios, es decir, las etapas de desequilibración o crisis, vendrían a representar oportunidades reales de desarrollo normativo. Si queremos ver este hecho circularmente, nos podemos hacer la siguiente pregunta: ¿representan las crisis oportunidades de desarrollo o más bien es el desarrollo el que 
le ofrece un marco de referencia a las crisis? A continuación, presentamos los estadios sociocognitivos acompañados de sus principales características (cuadro 3):

\section{Cuadro 3. Modelo neoconstructivista de los estadios sociocognitivos del desarrollo normativo (propuesto por el autor)}

\begin{tabular}{|c|c|}
\hline $\begin{array}{c}\text { Estadios del } \\
\text { desarrollo normativo }\end{array}$ & Características principales \\
\hline $\begin{array}{l}\text { Estadio instrumental } \\
\text { (diferenciación) }\end{array}$ & $\begin{array}{l}\text { Desarrollo de esquemas normativos para regular las actividades con el } \\
\text { entorno físico. Poseen un carácter esencialmente económico y material } \\
\text { (producción de bienes de consumo y de protección). Este estadio } \\
\text { aparece con el desarrollo de instrumentos y técnicas en la lucha por } \\
\text { sobrevivir y con el surgimiento de los primeros grupos humanos. }\end{array}$ \\
\hline $\begin{array}{l}\text { Estadio motivacional } \\
\text { (integración) }\end{array}$ & $\begin{array}{l}\text { Desarrollo de los primeros esquemas de normación social, } \\
\text { dominados por un pensamiento mágico-animista. Se crean vínculos } \\
\text { étnicos y las estructuras normativas se enmarcan en prácticas } \\
\text { rituales. Las reglas se acatan para obtener recompensas y evitar } \\
\text { castigos (motivos primarios). }\end{array}$ \\
\hline $\begin{array}{l}\text { Estadio estratégico } \\
\text { (diferenciación) }\end{array}$ & $\begin{array}{l}\text { Surgen diferencias individuales y con ellas normativas clasistas } \\
\text { en relación con la capacidad de mantener el control y el equilibrio } \\
\text { interno y externo, ya militarmente, ya religiosamente (control de } \\
\text { la naturaleza). Las normas sociales están dominadas por figuras } \\
\text { míticas y heroicas (caudillos, dictadores, etc.) y tienen un carácter } \\
\text { utilitarista y estratégico: "ojo por ojo, diente por diente" y "te doy, } \\
\text { para que me des". }\end{array}$ \\
\hline $\begin{array}{l}\text { Estadio moral } \\
\text { (integración) }\end{array}$ & $\begin{array}{l}\text { Surge la intención moral o altruista (en oposición a la egoísta y } \\
\text { estratégica) en la regulación normativa del comportamiento social. } \\
\text { Es un orden social determinado por un Dios único (rey metafísico) } \\
\text { que reina sobre el cielo (paraíso prometido) y la tierra. Se crean } \\
\text { estructuras religiosas que norman sobre lo que es bueno y malo, a } \\
\text { través de principios absolutistas y no negociables. Son estructuras } \\
\text { rígidas, patriarcales y jerárquicas, donde la culpa se utiliza también } \\
\text { como instrumento represivo (puritanismo religioso, confucianismo, } \\
\text { fundamentalismo islámico). }\end{array}$ \\
\hline $\begin{array}{l}\text { Estadio institucional } \\
\text { (diferenciación) }\end{array}$ & $\begin{array}{l}\text { Apoyados por una ciencia positivista, los organismos sociales } \\
\text { se emancipan de la normativa moral y surgen en su lugar } \\
\text { estructuras humanistas, donde ahora se resalta el derecho a una } \\
\text { autonomía individual (derechos del hombre). Las normas son de } \\
\text { carácter secular, racional y aspiran a regular (institucionalizar) la } \\
\text { economía, la política y la moral. Esta institucionalidad normativa } \\
\text { es la base de los Estados nacionales modernos y las alianzas de } \\
\text { mercado. Las normas remarcan el acato a las reglas, las leyes, } \\
\text { los deberes y los derechos institucionalizados en la constitución } \\
\text { de un Estado-nación. Es una normativa cartesiana (a partir de la } \\
\text { Ilustración, Wall Street, neoliberalismo). }\end{array}$ \\
\hline
\end{tabular}




\begin{tabular}{|l|l|}
\hline $\begin{array}{l}\text { Estadio constructivista- } \\
\text { sistémico (integración) }\end{array}$ & $\begin{array}{l}\text { Transición de las estructuras normativas positivistas y racionales } \\
\text { hacia una teoría del conocimiento que integra la autodeterminación } \\
\text { (constructivismo) y la interdependencia organísmica (teoría de } \\
\text { sistemas). Estas nuevas estructuras normativas, donde predominan } \\
\text { las redes internacionales y la sensibilidad social y ecológica, } \\
\text { deberán superar un racionalismo frío y calculador. Integración de la } \\
\text { diversidad y la pluralidad basada en la construcción de estructuras } \\
\text { normativas flexibles y viables, las que pueden ser en todo } \\
\text { momento sujeto de negociación y reconstrucción. }\end{array}$ \\
\hline
\end{tabular}

Fuente: elaboración propia.

Al estadio de incorporación de esquemas instrumentales a las estructuras biológicas de regulación lo llamamos estadio instrumental, en el que el organismo se emancipa de sus estructuras biológicas y las amplía a través de la construcción de esquemas o normas instrumentales. A través de estas estructuras, el actor combina mentalmente (reversibilidad) los objetos con los que interactúa, a fin de resolver los problemas adaptativos que se le presentan. Estas estructuras mentales instrumentales forman ahora la base del organismo para empezar a descubrir, respectivamente construir una realidad interna (mapa del entorno), que se equilibre con la realidad externa. Este primer estadio sociocognitivo le permite al actor coordinar sensaciones y movimientos en el uso y la construcción de instrumentos.

A partir de la necesidad de usar los distintos instrumentos en forma coordinada, ocurre una descentralización de las normas instrumentales, por lo que ahora el ser humano empieza un nuevo equilibrio y donde el objeto adquirirá un carácter social. Los esquemas ahora norman motivos (impulsos, intenciones individuales) y así coordinan el uso de instrumentos. A esta estructura cognitiva Piaget (1971a) la llamó estadio preoperativo (prelógico) y nosotros lo llamamos estadio motivacional. El pensamiento prelógico del estadio motivacional es unidimensional, es decir, emite juicios y conclusiones sobre la base de imágenes y símbolos mentales (representaciones motivacionales), entre los cuales, sin embargo, no existen vinculaciones causales fijas ni constantes - percibe acontecimientos y cambios naturales con carácter ilusorio como reales- que es característico de estructuras sociales preestatales, como clanes y tribus.

La próxima descentralización normativa desemboca en el estadio operativo o lógicoconcreto (Piaget, 1971a), al cual llamamos estadio estratégico. Es decir, este pensamiento normativo es de tipo estratégico y organiza las representaciones motivacionales (motivos) de los actores. Estas estructuras normativas son bidimensionales, de tal manera que los individuos pueden ya emitir juicios y conclusiones a través de la formación de sistemas de clases, relaciones y cantidades. Estas estructuras poseen características lógicas constantes, pero que se basan exclusivamente en acontecimientos y en objetos 
de carácter concreto. Estas estructuras normativas operacionales están determinadas por esquemas de carácter concreto, es decir, con un equilibrio empírico, en el que los individuos coleccionan información e investigan al mundo solo a partir de su horizonte físico. El pensamiento del estadio estratégico persigue la satisfacción de intereses y necesidades egoístas, forma clases sociales y utiliza a otros individuos como instrumento de trabajo (esclavitud). Surgen los primeros Estados y se empieza a conservar y a recordar acontecimientos pasados (surge la historia) a través de mitos y leyendas.

En el próximo equilibrio - estadio moral- el pensamiento lógico-concreto pasa de ser sujeto a ser objeto del conocimiento normativo, es decir, posee ahora un carácter abstracto y puede así coordinar las estructuras normativas concretas (estrategias). Lo actual, lo presente, se percibe solo como una posibilidad entre muchas, es decir, ocurre una transformación de lo físico (concreto, finito) a lo metafísico (inmaterial, espiritual). $\mathrm{El}$ actor social ahora son normas morales y, con estas, coordina las diferentes estrategias individuales. Socialmente se crea una normativa de comportamiento a través de principios absolutistas, donde una violación de las normas y reglas tiene consecuencias graves y su acatamiento conduce a la virtuosidad y a la salvación eterna. Este equilibrio normativo es característico de los Estados feudales.

En el estadio institucional (estadio formal de Piaget), los actores sociales se descentralizan de las estructuras normativas morales. El nuevo actor social puede ahora utilizar la capacidad de abstracción para construir el mundo de diferentes maneras a través de afirmaciones, hipótesis, conclusiones y abstracciones con carácter científico. Ahora los juicios se emiten a través de la construcción de sistemas (instituciones) que abarcan todas las relaciones y consecuencias posibles, y que poseen la capacidad de aislar hipotético-deductivamente variables y de comprobar hipótesis en forma abstracta. Las instituciones coordinan ahora las normas morales a través de un pensamiento científico y racional. El mundo se percibe ahora como una estructura racional que está controlada por leyes naturales, las cuales pueden ser aprendidas, controladas y manipuladas por instituciones nacionales y transnacionales. El Estado-nación es característico de este equilibrio.

El estadio constructivista-sistémico (estadio posformal neopiagetiano) presenta estructuras normativas sistémicas de carácter pluralista que deberán coordinar las diferentes instituciones normadoras a través de métodos sistémicos. Esta forma de pensar acentúa el diálogo y la interacción social, los cuales deberán ser realizados por actores sociales transparentes y abiertos que se definen solo en su relación con otros. El actor social ahora es comunicación (interacción circular) y coordina (tiene) instituciones. Este estadio implica la integración y coordinación de la diversidad y de la pluralidad sobre la base de la construcción de jerarquías naturales. Las estructuras normativas sistémicas intentan abarcar tanto niveles verticales como horizontales del desarrollo normativo 
general. El estadio constructivista-sistémico percibe la contradicción (diferenciación) como motor del desarrollo; sin embargo, dichas contradicciones desembocan en algún momento en procesos de equilibración o reintegración.

Utilización práctica de los estadios sociocognitivos. Durante la operacionalización sistémica (orden de red y consensual) será importante definir desde qué estadios sociocognitivos se basan las posiciones, argumentaciones y decisiones que dirigen las acciones de los distintos miembros de un sistema nacional, regional o mundial. De esta manera, se podrán coordinar mejor las distintas estructuras normativas, si es que, por ejemplo, se entiende la posición sociocognitiva de los indígenas amazónicos (estadio motivacional) y la de las empresas transnacionales de explotación de los recursos naturales (estadio institucional), o del problema del terrorismo como un conflicto entre el estadio moral y el estadio institucional, o del conflicto negociador entre Grecia (estadio estratégico) y el resto de los miembros de la Unión Europea (estadio institucional).

De la misma manera, desde nuestra perspectiva neoconstructivista, la historia ya no representa un medio de almacenamiento de datos objetivos que sean independientes de la actividad del conocer y a los que se pueda recurrir en casos específicos de necesidad, con el fin de explicar y justificar nuestras acciones. Nosotros observamos la historia más bien como un depósito de materiales de construcción (recursos normativos) dentro de la actividad u operaciones normativas de un organismo social. La historia depende así de la estructura sociocognitiva que la describa, la explique y la valore (interpretación), y que al mismo tiempo sea capaz de reactivar y reestructurar -ella misma- los esquemas normativos y valorativos que ha almacenado y conservado durante el proceso del desarrollo de su propia identidad.

Si la percepción del entorno que realiza un organismo social significa en primera instancia "interpretación" - a través de la asimilación que ejercen los esquemas normativos de cada estadio sobre el objeto-, la función de la historia vendría a ser para él "validación o confirmación", en la medida en que ella le garantiza la conservación y utilización de las experiencias pasadas, en especial, de aquellas que le son útiles para justificar las acciones u operaciones normativas que está realizando actualmente, y con las cuales además se identifica (selección perceptiva). Las representaciones narrativas de la historia podrían ser así también una ampliación acomodadora de la percepción original, ya que son capaces de transportar y reestructurar significaciones de un periodo sociocognitivo a otro (recontextualización).

Nuestro enfoque neoconstructivista diferencia entre historia en un sentido amplio e historia en un sentido estrecho de la palabra. En un sentido amplio, historia es un medio de "conservación y reproducibilidad de conocimientos normativos", es decir, de pautas organizadas de pensamiento y comportamiento normativo, adquiridas por el ser 
humano a través de su desarrollo antropológico. Las estructuras operacionales colectivas de una determinada cultura no representan entonces un recuerdo histórico pasado, sino que son una realidad potencial actual para ella y por lo mismo están disponibles para ser utilizadas en la ocasión oportuna (recursos de adaptación). En sentido estrecho, la historia de una determinada región cultural significa la conservación de los hábitos o costumbres normativas - vistas como resultados del aprendizaje colectivo-, así como la evocación de aquellos hechos históricos significativos - a través de su descripción y narración hablada o escrita - que contribuyen al desarrollo y la conservación de una identidad cultural propia. Esto significa el recordar instituciones o acontecimientos experimentados en el pasado y que han desempeñado un papel significativo en el desarrollo de la propia cultura.

Por otro lado, todas las formas de evocación de hechos significativos que hace la historia están sujetas a errores, deformaciones y nuevas construcciones, ya que siempre se basan en construcciones o reconstrucciones de lo vivido realmente. Este fenómeno se explica asimismo a través del hecho de que todo actor social, para poder recordar, debe utilizar los mecanismos de la asimilación y la acomodación, los cuales - en esencia-solo son capaces de crear una interpretación adaptativa de la realidad que se pretende o se cree conocer. De esta manera, nuestra perspectiva neoconstructivista afirma que tanto la forma como la calidad de la capacidad de recordar cambian durante los distintos estadios del desarrollo sociocognitivo. El recuerdo histórico se vuelve cada vez más preciso en el transcurso del tiempo, pero solo en la medida en que durante ese tiempo la cultura en particular haya desarrollado estructuras sociocognitivas nuevas.

\section{Del estadio institucional al constructivista-sistémico}

Cada acto normativo presenta dos aspectos importantes: por un lado, el primer aspecto nos muestra las particularidades concretas de la actividad que se quiere normar, las que al mismo tiempo reflejan el nivel cognitivo de adaptación de los sistemas interactuantes (estadios sociocognitivos); el segundo aspecto, por otro lado, representa la parte generalizable y esquematizable de dicha actividad, la cual es la que normamos y que, además, constituye el fundamento de aquello que llamamos pensamiento normativo. La normación provoca, sin embargo, la sustitución de la actividad en particular por su forma generalizada y esquematizada. De esta manera, el concepto de operación se usa aquí como sinónimo de pensamiento normativo, ya que este representa una actividad u operación concreta, la cual fue interiorizada y normada por los sistemas interactuantes. El resultado de un acto de normación no se encuentra entonces fuera de la lógica interna de los esquemas operacionales normativos. Si, por un lado, tenemos que juzgar el éxito o el fracaso de una actividad u operación externa, necesitaremos solo la retroalimentación de nuestros sentidos físicos. Por el contrario, el resultado de un acto 
operacional normativo es percibido, entendido e interpretado solo de manera interna por la institución o sistema que lo ejecuta, debido a que dicho resultado ya fue antes anticipado por dicha institución (expectativa de asimilación).

A través del mecanismo de normación operacional formal (estadio formal de Piaget), el desarrollo del pensamiento normativo desembocó en las estructuras normativas institucionales o lógico-racionales. Estas fueron posibles, por un lado, debido al hecho de que el pensamiento normativo formal transforma las cosas del mundo en esquemas epistémicos o ideas, las que son más fáciles de manipular en forma ordenada. Por otro lado, el pensamiento normativo institucional o racional está también ligado al elemento principal que caracteriza las operaciones normativas formales, a saber, su capacidad de reversibilidad. Si la transformación mental de las actividades por normar y su inversión pueden unirse en una sola operación normativa, esta se libera, entonces, del vínculo que tiene con la causalidad espacial durante las interacciones concretas, así como de la continuidad ininterrumpida del factor tiempo que las caracteriza. De esta manera, la operación normativa racional se universaliza, es decir, se independiza del espacio y de los tiempos concretos.

El problema principal de esta universalización normativa es que el pensamiento racional o cartesiano sobre el que se basa el estadio institucional precisa de la dualidad, es decir, polariza. El conocimiento racional sin dualidad, sin la división en sujeto y objeto, en observador y observado no es posible. El pensamiento racional polariza al mundo y afirma que todo desarrollo depende de la racionalidad de nuestros actos. El problema implícito de esta posición racional es, sin embargo, querer hacer desaparecer la contradicción que trae consigo la polaridad y querer tratar de descubrir la verdad en un solo polo (el racional o verdadero). Para existir racional y objetivamente, necesitamos entonces un mundo polarizado, es decir, donde se deberá eliminar la irracionalidad y la subjetividad que impiden el desarrollo de la humanidad. La polaridad de la conciencia y normativa racional nos coloca constantemente ante dos posibilidades de acción y nos obliga a decidirnos por una de ellas. Siempre hay - por lo menos- dos posibilidades, pero nosotros solo podemos realizar una. Ya que tenemos que decidirnos, por lo menos procuramos que nuestra decisión sea sensata y correcta, es decir, racional. Y para ello necesitamos cánones de valoración universales con carácter racional. Así las decisiones se hacen más fáciles.

El sistema racional funciona bien y facilita las decisiones (uno no tiene más que hacer lo correcto y lo que está estipulado en las normas institucionales). Lástima que nuestro sistema de valoración y normación institucional, que nos ayuda a decidir racionalmente, sea cuestionado por otras culturas y otros Estados que profesan valores y normas distintas. Y todos quieren hacer lo correcto. Pero ćqué es lo correcto? Cada valoración y normación son subjetivas. Cada valoración depende del punto de vista del observador y de su sistema de referencia, por tanto, basada en él, siempre será correcta. El mundo globalizado no puede dividirse en lo que "debería ser" y por ende es bueno y justo, y 
lo que "no debería ser" y en consecuencia tiene que ser combatido y aniquilado. Este dualismo cartesiano de opuestos irreconciliables, verdad-error, bien-mal, dios-demonio, democracia-dictadura, no nos saca de la polaridad, sino que nos hunde más en ella.

Por otro lado, el pensamiento normativo sistémico, característico del estadio constructivista-sistémico, representa otro tipo de esquemas normativos. El acto normador de esta forma de pensamiento no se basa ya en el análisis racional causa-efecto, sino más bien resalta las interacciones $u$ operaciones circulares que ocurren entre los elementos de un sistema dado o que tienen lugar durante las actividades de coordinación entre diferentes sistemas (actividades de cooperación o integración). Las normas surgen como resultado de procesos de equilibración constante, los que obligan a los sistemas normativos a autoorganizarse a través de las funciones de la asimilación y de la acomodación.

La autoorganización organísmica vendría así a sustituir la razón como fuente normativa o de construcción de estructuras normativas que permitan un nuevo orden de regulación o gobernanza de las actividades sociales. Si fallan las funciones de adaptación de un sistema cualquiera, surgirán entonces estados normativos disfuncionales (bloqueo o inflexibilidad normativa), que poseen un carácter defensivo o de autoconservación y a los cuales llamaremos estados normativos precarios. Sobre estos estados normativos disfuncionales, los cuales son generadores de diferentes conflictos o sintomatologías (las que tienen la tarea de estabilizar el sistema de manera artificial - crear homeostasis-) no hablaremos en esta ocasión, debido a lo extensivo del tema y porque su descripción sobrepasaría los objetivos de este artículo.

La autoorganización controla ahora a la racionalidad científica, en la medida en que ahora aparece un observador (epistemólogo) del observador (el científico) que observa al mundo y así la epistemología descubre que tanto investigador como objeto investigado forman ambos parte de un mismo sistema, en el cual se están influenciando mutuamente en forma constante. Estos sistemas son de carácter cerrado, es decir que se separan y autolimitan del entorno a través de sus operaciones internas; en otras palabras, ellos justifican sus actividades sobre la base de sus mismas estructuras operacionales normativas. Las operaciones normativas solo se construyen sobre otras operaciones normativas. En un sistema cerrado (centralizado), el interior y el exterior del sistema solo existen para el observador epistémico que los observa desde otro sistema (descentralizado).

Como observador del observador que quiere conocer al mundo, Piaget (1930, 1975a, 1975b, 1975d) descubre que este (el niño) manipula los objetos que pretende comprender, es decir que para entenderlos los deberá primero manipular y a continuación se forma una imagen de estos (interioriza). En la medida en que el sujeto hace esto, cierra el círculo sensorio-motriz. Son las actividades neuronales del niño que investiga las que determinan su comportamiento observable (por ejemplo la inervación de los músculos que le permiten prender el objeto), y es el mundo objetual 
(que se opone a su aparato motor) el que se encarga de que otras de sus actividades u operaciones neuronales (la excitación de células sensoriales) se coordinen con las operaciones motrices. De esta manera, y a través de estas coordinaciones operacionales sensorio-motrices (esquemas normativos instrumentales), surgirán nuevas operaciones normativas (concretas, formales, sistémicas), que, en última instancia, son la representación interna del mundo investigado.

En otras palabras, durante la confrontación e interacción con los objetos (sistemas) el organismo social activa repetidamente las mismas operaciones normativas, a través de lo cual reconoce e identifica al objeto como el mismo objeto (asimilación). Esto es entonces a lo que llamamos "conocimiento" (una repetición operacional normativa). Sin embargo, desde la posición del observador que observa al investigador, no son las mismas características del objeto observado las que determinan su identidad, sino las mismas características (operaciones normativas) del sistema cognitivo o normativo del investigador. La identidad no son entonces las características que un determinado sistema posee, sino las características que un determinado observador o normador construye sobre el sistema con el que interactúa (esto es válido también para la autoobservación o autonormación y la definición de la propia identidad que hacen los agentes sociales de ellos mismos).

Por otro lado, es también a través de la interacción con los sistemas del entorno que se desarrollan y cambian las estructuras u operaciones normativas del sistema operacional de todo organismo social. Estas se autoorganizan en la medida en que el entorno no se deje asimilar y así se crea un desequilibrio (perturbación) entre las estructuras normativas (lo que pensamos del entorno) y cómo se comporta el entorno. Ahora el sistema social normativo (operacional) empieza a manipular de nuevo los sistemas del entorno, esta vez en forma de hipótesis u operaciones abstractas, para hacer las correcciones correspondientes que le permitan equilibrarse con el entorno (proceso de acomodación). Piaget $(1972,1983,1991)$ ve a los seres humanos como organismos, que durante sus intentos por conocer el mundo formulan preguntas y problemas. El progreso para el organismo social radica, entonces, en inventar nuevas formas de interrogar al mundo y de descubrir nuevas características de la realidad, en función de las preguntas e hipótesis autoplanteadas. El proceso de equilibración es sinónimo de autoorganización.

\section{Nuevas estructuras normativas (constructivista-sistémicas)}

La vida está siempre en constante desarrollo, de tal manera que las estructuras políticas y normativas de regulación (nacionales e internacionales) necesitan -en caso de grandes cambios en los contextos naturales y sociales- mecanismos de equilibración adecuados, a fin de poder adaptarse a las nuevas condiciones. Las estructuras 
normativas resultantes de dicha adaptación deberán, asimismo, estarse actualizando de tiempo en tiempo. De esta manera, surge la necesidad para nuestra sociedad de la construcción constante de nuevas estructuras normativas cualitativas, las cuales deberán ser integradas en las ya existentes.

El modelo constructivista sistémico no entiende a la sociedad como una agrupación de individuos que solo luchan por obtener ventajas e imponer sus intereses personales y a los que el Estado institucional, a fin de conservar el orden y la paz social, deberá ponerles límites a través de la construcción de estructuras normativas. Para dirigir y normar a la sociedad, el Estado moderno (institucionalista) se apoya sobre los conocimientos de unos pocos expertos (entre ellos la ciencia como dogma), cuya superioridad ante el conocimiento práctico con potencial autoorganizativo existente en el seno de los sistemas normativos informales es dudosa. Por otro lado, el modelo constructivistasistémico (Pastrana y Sánchez, 2014) entiende a la sociedad más bien como una totalidad sistémica estructurada a través de redes relacionales inter-y transubjetivas, cuyas actividades autoorganizacionales representan una fuente constante de equilibración, es decir, de creación de estructuras normativas más flexibles. De esta manera, las normas sistémicas están mejor preparadas para regular las nuevas estructuras globales, ya que son más flexibles, y con esto, dan a los organismos sociales la oportunidad de utilizar nuevas y mejores estrategias de acción de manera más rápida y efectiva.

Nuestro enfoque neoconstructivista, basado en la teoría piagetiana del desarrollo cognitivo, entiende el desarrollo del sistema normativo mundial como la adquisición e integración de nuevas estructuras normativas (operaciones sistémicas), pero basadas en las estructuras anteriores, es decir, como desarrollo cualitativo. Esa concepción del desarrollo, como una construcción de estructuras más complejas, más amplias y más flexibles, presupone que la estructura o sistema de regulación anterior sea condición ineludible para la construcción de una nueva estructura normativa de regulación global que garantice el equilibrio entre contexto ambiental, contexto social y actores sociales. En relación con lo dicho, y basándonos en Piaget (1976), el desarrollo de estructuras normativas sistémicas deberá diferenciar cuatro tipos de equilibrios interactivos:

1. El equilibrio entre el sistema normativo global y el entorno físico-natural (o entre asimilación y acomodación).

2. El equilibrio entre diferentes sistemas normativos regionales, en general, entre subsistemas normativos.

3. El equilibrio entre un sistema normativo regional y el sistema normativo global, en general, entre subsistemas regionales y el sistema global.

4. El equilibrio entre organizaciones normativas estatales y su sistema normativo regional, en general, entre Estados (orientados internacionalmente) y sus regiones. 


\section{Gobernanza global sistémica}

La capacidad de interactuar con su entorno es la base fundamental del desarrollo organísmico y, por ende, de la supervivencia de todos los seres vivos. Los individuos y las sociedades construyen sus normativas de identidad a través del intercambio con sus contextos sociales de referencia, dentro de los cuales ellos existen y se desarrollan. En la época de la globalización, las estructuras normativas de identidad necesitan entonces estar conformadas con patrones de comportamiento variables y flexibles. Este hecho se hace más evidente al observar el trabajo de las organizaciones internacionales, las cuales tienen que estar mediando constantemente entre contextos culturales y regionales diferentes. La precondición para interacciones exitosas con este nuevo mundo de la variedad y pluralidad será entonces una organización activa, fuerte y capaz de adaptarse rápidamente a los cambios inesperados provenientes de su entorno. Para poder ser capaz de interactuar constantemente en contextos sociales diferentes y con carácter multicultural, sería recomendable que las organizaciones sociales (nacionales e internacionales) lograran estructurarse en forma más flexible y variable, para así y durante su accionar mediador y normativo poder tener más acceso e influencia sobre las estructuras que quieren normar.

La nueva realidad global que presenta el mundo internacional es un evento que desequilibra las normativas institucionales del Estado-nación y que, consecuentemente, exige transformaciones estructurales de normación en estos (equilibración). Los procesos globales han venido generando una conciencia universal en los actores sobre sus impactos, los que exigen de ellos un alto grado de cooperación internacional y el desarrollo de estrategias y programas específicos y conjuntos. En este nuevo contexto de red, la gobernanza global surge como un sistema basado en la cooperación internacional, que en el sistema político mundial integra actores estatales y no estatales, tales como organizaciones internacionales, la sociedad civil global, empresas transnacionales, medios de comunicación y comunidades epistémicas (Pastrana y Sánchez, 2014).

De lo anterior podemos deducir que en la actual época globalizada la hipótesis más viable para explicar los problemas disfuncionales de carácter normativo que presentan algunas organizaciones o actores sociales afectados deberá buscarse más bien en la capacidad deficiente que estos presentan al intentar integrar la gran variedad de tareas que les exige el actual entorno global (ambientales, económicas, políticas, étnicas, culturales, etc.). El problema típico actual del Estado-nación -basado en la normación institucional y racional- es que desarrolla disfunciones normativas (equilibrios precarios), probablemente como producto de una incapacidad crónica de no poder o querer adaptarse al mundo posmoderno, el que así se ha convertido para ellos en incontrolable e impredecible, es decir, en un mundo anárquico, indiferenciado, incoherente y por tanto no gobernable. Este hecho impide al actor moderno desarrollar 
una identidad competente de regulación efectiva, lo cual como consecuencia vendría a impedirle adaptarse a su contexto de forma adecuada. Es a partir de entonces cuando estos actores tratan de refugiarse en la seguridad que les dan sus viejos patrones de comportamiento (estados regresivos: defensivos o agresivos), los que tienden a filtrar y a disociar partes importantes de la realidad.

Por otro lado, la variedad del mundo posmoderno exige asimismo de todos los actores una ampliación de la propia identidad estructural a lo interno, lo cual significa poder abrirse a la pluralidad de formas y posibilidades estructurales que coexisten en los propios sistemas sociales. Los actores sociales capaces de reconocer en sus propias estructuras sociocognitivas el potencial de recursos humanos que poseen seguramente van a estar mejor capacitados para desarrollar mejores estrategias de diferenciación e integración normativas (equilibración) y además reducir así los conflictos internos, en la medida en que las nuevas normativas les permitan aumentar su tolerancia ante las diferencias, las ambigüedades y las ambivalencias sociocognitivas presentes en sus territorios de influencia. Si como actor social dejas existir diferentes verdades y formas de vida en tus estructuras internas, entonces te será más fácil vivenciar y entender a otros actores sociales y culturales y a sus contextos de referencia.

El surgimiento de la gobernanza global como nueva estructura política y normativa de regulación u orden mundial está siendo el resultado de procesos de acomodación y por ende de descentralización y construcción aproximativa emprendidos por los viejos y nuevos actores sociales. Estos procesos acomodadores surgen debido a la incapacidad de las viejas estructuras de dar respuesta a las nuevas exigencias de regulación que plantean los problemas globales. La gobernanza global es entonces una estructura en formación que deberá permitir la cooperación de los diferentes actores y que ya está tomando la forma de sistemas de red llamados regímenes internacionales, así como de la ejecución de programas y estrategias específicas que los desarrollen. Una gobernanza global hace entonces necesaria la transferencia de competencias de regulación a instituciones supranacionales, es decir, a través de la construcción de una red de regímenes internacionales que impongan deberes específicos en los respectivos ámbitos a los diferentes actores globales (Pastrana y Sánchez, 2014).

\section{Estado internacional}

Según nuestro enfoque neoconstructivista, la identidad de un Estado cualquiera representa la historia evolutiva de sus estructuras sociocognitivas (Pastrana y Sánchez, 2014). Esa actividad evolutiva está teniendo lugar a cada momento, ya provocada por las interacciones provenientes del medio exterior, ya producto de la propia dinámica interna del Estado en cuestión. El neoconstructivismo postula la tesis de que las nuevas estructuras internacionales solo pueden surgir sobre la base de las anteriores. En este 
sentido, global governance no significa ni gobierno global ni el final del Estado como tal, sino, por el contrario, que este descentralice y amplíe sus actuales estructuras normativas institucionales, a fin de asumir el liderazgo en relación con la construcción de las nuevas estructuras normativas globales (constructivista-sistémicas). Esto significa que el Estado deberá adoptar una nueva forma, la cual vendría a reflejar el estadio sociocognitivo de las estructuras constructivista-sistémicas de normación. A este Estado en formación el neoconstructivismo lo llama el Estado internacional (Pastrana y Sánchez, 2014).

A nuestra manera de ver las cosas, el Estado internacional representa el actor global clave en la coordinación que deberá tener lugar entre los diferentes sistemas multinivel (sublocal, local, nacional, regional, interregional y global). El Estado internacional, en su nueva identidad sistémica, deberá asumir un rol completamente diferente del anterior, y en el que pueda desarrollar mecanismos y estrategias de coordinación y cooperación; es decir, instrumentos autoorganizativos que faciliten, no solo la elaboración de consensos, sino la implicación de todos aquellos actores que sean necesarios para la elaboración y el alcance de las metas normativas y de integración planteadas en las agendas regionales y globales con carácter multinivel; en otras palabras, capacidades e instrumentos normativos que les permitan movilizar los intereses en juego e integrar los recursos de que dispone cada uno de los actores: políticos, jurídicos, financieros, cognitivos, informativos, etc.

La identidad o equilibrio en el que nuestro enfoque neoconstructivista coloca el Estado internacional representa el estadio constructivista-sistémico. Este estadio implica la integración y coordinación de la diversidad y de la pluralidad de esquemas estructurales sobre la base de la construcción de jerarquías naturales. Dicha construcción cognitiva intenta abarcar tanto niveles verticales como horizontales del desarrollo. Hay muchos recursos (esquemas sociocognitivos) en la sociedad global, pero estos se encuentran descoordinados y dispersos. La gobernanza multinivel de los Estados con carácter internacional tiene, entonces, que facilitar la agrupación y la gestión compartida de este conjunto de recursos, lo cual significa que ella se expresa a través de la creación y regulación de redes (sistemas) que permiten una participación pluralista, aunque no igualitaria, tomando para esto, como criterio de representatividad, las jerarquías naturales de desarrollo sociocognitivo (Pastrana y Sánchez, 2014).

En el estadio de las operaciones constructivista-sistémicas, los actores no solo aceptan las contradicciones existentes, sino que ellos buscan de manera intencional crear nuevas, con el fin de impulsar el desarrollo de estructuras de identidad sistémica. Los sistemas existen solo si los percibimos u objetivamos, es decir, los construimos internamente (cognitivamente), en esa misma medida son de naturaleza flexible y están sujetos a constantes procesos de remodelación y equilibración. Los sistemas internacionales no son así rígidos, tienen fronteras permeables, están interconectados y son parte de muchos otros sistemas con jerarquías naturales. 
La conciencia constructivista-sistémica reconoce que la actividad contextual e intersubjetiva es la principal variable reguladora en la efectividad de las tareas de organización estructural. Cuanto más pueda adaptar el Estado internacional su conducta a la situación concreta (fenómenos de globalización), más eficaces serán sus esfuerzos de equilibración interna y de integración (influencia) internacional. Esto significa también la adaptación de las medidas de gobernanza: 1) al nivel del desarrollo sociocognitivo de los actores (nacionales o internacionales) y 2) a la activación, coordinación y utilización de sus recursos (capacidades y motivaciones) (Pastrana y Sánchez, 2014).

Sobre la base de la combinación de estos dos factores se pueden construir diferentes estrategias de gobernanza (local, nacional, regional, multinivel y global). En primer lugar, tenemos la estrategia directiva (dirigir, ordenar, controlar). Esta estrategia se aplica en situaciones donde los actores no poseen ni las capacidades ni la motivación necesaria para realizar las tareas y metas por alcanzar. Aquí el Estado es el que establece los qué, cuándo, dónde y cómo.

En segunda instancia, encontramos la estrategia de persuasión (convencer, supervisar, tutorizar). Dicha estrategia se aplica en situaciones en las que los actores poseen las capacidades para realizar las tareas, pero no la motivación necesaria. El Estado explica su visión y sus metas e intenta convencer a los actores para que las acepten y se impliquen en las tareas correspondientes. Se le denomina persuasión, porque el Estado redefine o recontextualiza las metas individuales, se mantiene receptivo para reconocer las dificultades y anima a establecer relaciones de participación y cohesión.

En tercer lugar, se ubica la estrategia de asesoramiento (animar, activar). Esta estrategia se aplica en la presencia de actores con capacidades y motivos suficientes para asumir la responsabilidad de sus propios proyectos. El Estado traslada más responsabilidad a los actores, los alienta a tomar decisiones y facilita la colaboración y compromiso entre ellos. Tanto el Estado como los actores comparten los planes y la dirección. El papel principal del Estado es, entonces, el de facilitar y fomentar la participación de aquellos actores, quienes ya han alcanzado un mayor desarrollo en las actividades por realizar, así como una adecuada integración social.

Como cuarta opción tenemos la estrategia de delegación (acompañar, reflejar). Esta estrategia implica un alto nivel de desarrollo sociocognitivo de los actores y un alto grado de capacidades y de motivación en relación con la actividad por realizar. El Estado observa y acompaña. Los actores mismos serán quienes tomen las decisiones y lleven a cabo la realización y la gobernanza de las tareas. Esto significa que el Estado entrega a los actores la responsabilidad y la instrumentación de la toma de decisiones; es decir, estimula y apoya el funcionamiento autónomo de los actores. Su papel es garantizar una buena retroalimentación.

Por tanto, el Estado internacional deberá poseer capacidades diagnósticas y estructuras de gobernanza flexibles, con el fin de determinar: 1) el nivel de desarrollo 
sociocognitivo de los actores, 2) el nivel de dificultad de las exigencias dadas en una determinada actividad reguladora y 3) ser lo suficientemente flexible y creativo para asumir mecanismos de gobernanza acordes con la actividad y el nivel de los actores implicados (Pastrana y Sánchez, 2014).

La fortaleza del nuevo Estado con orientación internacional no se basa ya en su tamaño o grado de presencia en la sociedad ni en vincularse con una idea estática de soberanía, sino en sus capacidades interactivo-dialécticas y de consenso unificador, a fin de poder lidiar con el entorno global. Esta forma de gobierno (gobernanza) necesita en gran medida un gran capital social (Putnam, 1993). El capital social hace referencia al conjunto formado por la confianza social, las normas y las redes que todo el conjunto de actores pueden constituir para resolver los problemas comunes.

En este orden de ideas, la gobernanza del Estado internacional exige un cambio en el equilibrio entre Estado y sociedad civil. Este cambio se pone de manifiesto en una ciudadanía activa y autónoma, y se vincula a debates y soluciones más amplios en torno a una democracia deliberativa y participativa. Este nuevo equilibrio exige una sociedad civil fuerte, por un lado, diferenciada en subsistemas con perfiles claros (distribución de poder), y por otro, con un alto grado de cohesión social (identificación y responsabilidad con la totalidad). La sociedad civil deberá entonces desarrollar actores corporativos autónomos y hábiles, con el fin de poder negociar con otros actores (estatales y no estatales) que representen diferentes demandas e intereses sociales opuestos. Se deberá aspirar también a la institucionalización de formas de negociación dialécticas y múltiples (redes de negociación) entre todos los actores sociales, así como a una distribución descentralizada de las responsabilidades de regulación en las nuevas estructuras sistémicas de gobernanza local, regional y global (Sánchez y Pastrana, 2012).

Los mecanismos de regulación social existen, entonces, en forma descentralizada, pero siempre con la posibilidad de intervención estatal (moderación). La gobernanza representa así una especie de gestión de redes de acción, las cuales vendrían a reemplazar al Gobierno como centro director de la sociedad. Este nuevo equilibrio marca el paso del concepto de gobierno (regulación institucional-jerárquica) al concepto de gobernanza (regulación a través de redes de acción). El objetivo inmediato sería encontrar formas de acoplamiento más efectivas, originales y flexibles entre las estructuras estatales y la sociedad civil, y también la producción de consensos negociados en las redes de actores, de tal manera que facilite la formación de una política que encuentre más aceptación que resistencia y que sea capaz de enfrentar los nuevos retos globales (Sánchez y Pastrana, 2012).

En resumen, en nuestra visión neoconstructivista (estadio sistémico), basada en los estadios del desarrollo cognitivo de Piaget, el Estado internacional deberá desarrollar mecanismos de coordinación basados en una jerarquía natural, la cual deberá garantizar el orden en que se han venido desarrollando evolutivamente las diferentes estructuras 
de regulación social: instrumental (sensorio-motriz), motivacional (preoperacional), estratégica (operacional concreta), moral (preformal), institucional (formal) y constructivista-sistémica (posformal). Una estructura jerárquica natural presupone una actividad coordinadora del Estado con carácter sistémico, la cual a su vez deberá ser capaz de garantizar la integración y cohesión de los distintos niveles y contextos de las actividades de gobernanza, aun a pesar de las asimetrías de desarrollo existentes entre ellas (estructuras sociocognitivas), de los diferentes tipos de recursos (historia) predominantes en cada una (materiales, emocionales o simbólicos) y de los distintos espacios en que ellas se realizan (sublocal, local, regional, nacional o supranacional) (Sánchez y Pastrana, 2012).

\section{Régimen internacional constructivista-sistémico}

En su esencia, un régimen internacional con carácter constructivista-sistémico se entiende como un sistema de normas (con carácter circular o dialéctico) que están especificadas en acuerdos multilaterales celebrados entre un conjunto de actores globales y con el fin de regular acciones de carácter regional o internacional sobre un tema específico o sobre un conjunto de temas interrelacionados. La razón del surgimiento de los regímenes constructivista-sistémicos es conseguir un equilibrio entre la estructura global y sus actores, así como entre los actores mismos.

Una norma con carácter constructivista-sistémico se entiende aquí como un esquema jurídico que está diseñado para coordinar estructuras sociocognitivas diferentes, tanto en forma horizontal (pluralismo) como vertical (multinivel). Aquí se hará necesario, quizá, el desarrollo de un nuevo concepto de justicia internacional, así como la construcción de nuevos instrumentos jurídicos que superen los puramente racional-dogmáticos y puramente estatistas (basados solo en actores estatales). De esta manera se ampliaría cualitativamente el círculo de actores que participen activamente en el surgimiento de las nuevas normas internacionales. Una posible base, para el desarrollo de nuevas estructuras jurídicas en el concierto internacional, sería tomar de referencia la "fase del contrato social" (estadio cinco) ubicada dentro de las fases posconvencionales de la teoría del desarrollo moral de Kohlberg (1958, 1963, 1973, 1976, 1984). La teoría de Kohlberg está, asimismo, basada en la teoría estructural-genética de Piaget.

\section{Conclusión}

El enfoque de carácter neoconstructivista presentado en este trabajo está basado en la epistemología genética de Piaget, la cual es una teoría interaccionista y constructivista con carácter organísmico y dialéctico. Consecuentemente, nuestra perspectiva neoconstructivista define a los organismos sociales como actividad normativa en constante evolución y, con el fin de sustentar dicha afirmación, se basa en dos postulados básicos: la idea de que los sistemas sociales construyen la realidad que perciben (constructivismo) y el 
concepto que afirma que los sistemas sociales se desarrollan en forma circular durante estadios alternados de diferenciación o transformación y de integración o estabilidad (desarrollo dialéctico). Ambos postulados remarcan de manera diferente que detrás de cada norma o sistema normativo se oculta un proceso evolutivo, que es el que en última instancia la crea o la deja surgir.

Asimismo, nuestro enfoque neoconstructivista describe y explica la necesidad de descentralizar las actuales estructuras normativas dominantes y pasar del estadio de estructuras institucionales, característico de la modernidad, a un estadio constructivistasistémico, de estructuras normativas con carácter posmoderno. La hipótesis neoconstructivista anterior, y la que está basada en una cierta ampliación que hacemos de los estadios cognitivos del desarrollo propuestos por la epistemología genética piagetiana, postula la existencia de estadios sociocognitivos que habrían surgido en el devenir de la evolución de las estructuras sociales.

Finalmente, nuestra propuesta neoconstructivista postula la tesis de que toda nueva estructura normativa solo puede surgir sobre la base de las anteriores. En este sentido, el surgimiento de las estructuras constructivistas sistémicas de normación no vendría a significar el final del Estado como tal (ni como actor principal en las regulaciones internacionales), sino, por el contrario, que este descentralice y amplíe sus actuales estructuras normativas de regulación con carácter institucional. Esta transformación normativa implicaría que el Estado deberá adoptar una nueva forma sociocognitiva de regulación, tanto de sus actividades internas como las que abarcan su política exterior. A este Estado emergente nuestro enfoque neoconstructivista lo llama el Estado internacional.

\section{Referencias}

Bateson, G. (1967). Kybernetische Erklärung. En Ökologie des Geistes (pp. 515-529). Fráncfort: Suhrkamp.

Bateson, G. (1971). Die Kybernetik des „Selbst“. Eine Theorie des Alkoholismus. En Ökologie des Geistes (pp. 400-435). Fráncfort: Suhrkamp.

Bateson, G. (1979). Geist und Natur. Eine notwendige Einheit. Fráncfort: Suhrkamp.

Beck, A. (1979). Cognitive therapy and the emotional disorders. Nueva York: Meridian.

Bellah, R. N. (2011). Religion in human evolution: From the paleolithic to the axial age. Cambridge, Londres: Harvard University Press.

Bertalanffy, L. von (1968). General systems theory. Nueva York: George Braziller.

Foerster, H. von (1973). Über das Konstruieren von Wirklichkeiten. En H. von Foester, Sicht und Einsicht. Versuche zu einer operativen Erkenntnistheorie (pp. 25-41). Heidelberb: Carl-Auer. 
Foerster, H. von (1974). Cybernetics of cybernetics. BCL Report, 73.38. Urbana (University of Illinois).

Foerster, H. von (1984). Erkenntnistheorie und Selbstorganisation. Delfin, 4, 6-19.

Foerster, H. von (1988). Abbau und Aufbau. En F. B. Simon, Lebende Systeme. Wirklichkeitskonstruktionen in der systemischen Therapie (pp. 32-51). Taschenbuchaufgabe, Fráncfort Suhrkamp.

Fowler J. (1991). Stages of faith and religious development. Nueva York: Crossroad.

Gebser, J. (1999). Ursprung und Gegenwart. Neukirchen: Novalis-Verlag.

Glasersfeld, E. von (1985). Konstruktion der wirklichkeit und des Begriffs der Objektivität. En H. Gumin y A. Mohler, Einführung in den Konstruktivismus (pp. 1-26). Múnich: Oldenbourg.

Habermas, J. (1976). Zur Rekonstruktion des historischen Materialismus. Fráncfort: Suhrkamp.

Habermas, J. (1985). Der philosophische Diskurs der Moderne. Fráncfort: Suhrkamp.

Habermas, J. (2001). Die Zukunft der menschlichen Natur: auf den Weg zu einer liberalen Eugenik? Fráncfort: Suhrkamp.

Habermas, J. (2005). Zwischen Naturalismus und Religion: philosophische Aufsätze. Fráncfort: Suhrkamp.

Husserl, E. (1950). Cartesianische Meditationen und Pariser Vorträge. La Haya: Martinus Nijhoff Publishers.

Jaspers, K. (1937). Descartes und die Philosophie. Berlín: De Gruyter.

Kegan, R. (1982). The evolving self. Cambridge, MA: Harvard University Press.

Kegan, R. (1994). En over our heads: The mental demands of modern life. Cambridge, MA: Harvard University Press.

Kohlberg, L. (1958). The development of modes of moral thinking and choice in the years ten to sixteen (Tesis de doctorado, University of Chicago, Illinois, Estados Unidos).

Kohlberg, L. (1963). The development of children's orientations toward a moral order. Human Development, 6(1-2), 11-33.

Kohlberg, L. (1969). Stage and sequence: The cognitive-developmental approach to socialization. En D. A. Goslin (ed.), Handbook of socialization theory and research (pp. 347-480). Nueva York: Rand McNally. 
Kohlberg, L. (1973). Continuities and discontinuities in childhood and adult moral development revisited. En O. Baltes y K. W. Schaie (eds.), Life-span development psychology. Nueva York: Academic.

Kohlberg, L. (1976). Moral stages and moralization. En R. Lickona (ed.), Moral development and behavior (pp. 31-53). Nueva York: Holt, Rinehart, and Wiston.

Kohlberg, L. y Candee, D. (1984). The relationship of moral judgment to moral action. En L. Kohlberg (ed.), Essays on moral development (vol. 2, pp. 498-581). San Francisco: Harper y Row.

Lenski, G. (1963). The religious factor: A sociological study of religion's impact on politics, economics, and family life. Westport, CT: Greenwood Press.

Luhmann, N. (1984). Soziale Systeme. Grundriss einer algemeinen Theorie. Fráncfort Suhrkamp.

Luhmann, N. (1988). Was ist Kommunikation? En F. B. Simon, Lebende Systeme. Wirklichkeitskonstruktionen in der systemischen Therapie (pp. 19-31). Fráncfort: Suhrkamp.

Luhmann, N. (1997). Die Gesellschaft der Gesellschaft. Fráncfort: Suhrkamp.

Maturana, H. y Varela, F. (1970). Biologie der Kognition. En H. Maturana, Erkennen: Die Organisation und Verkörperung von Wirklichkeit (pp. 32-80). Braunschweig: Vieweg.

Maturana, H. y Varela, F. (1984). Der Baum der Erkenntnis. Berba: Scherz.

Pastrana Buelvas, E. y Sánchez Mendioroz, Ángel (2014) Retos de la gobernanza global frente a una multipolaridad creciente. En Pastrana Buelvas, E. y Gehring, H. (eds.) (2014). Suramérica en el escenario global: gobernanza multinivel y birregionalismo. Bogotá: Pontificia Universidad Javeriana, Konrad Adenauer Stiftung, Universidad Santiago de Cali, pp. 23-83.

Pastrana Buelvas, E. y Gehring, H. (eds.) (2014). Suramérica en el escenario global: gobernanza multinivel y birregionalismo. Bogotá: Pontificia Universidad Javeriana, Konrad Adenauer Stiftung, Universidad Santiago de Cali.

Piaget, J. (1928). Judgment and reasoning in the child. Nueva York: Harcourt, Brace.

Piaget, J. (1930). The child's conception of physical causality. Londres: Kegan Paul.

Piaget, J. (1962). Comments. Supplement to Vygotsky, L. S. En Thought and Language. Cambridge, Londres: The MIT Press.

Piaget, J. (1964a). Development and Learning. En R. E. Ripple, V. N. Rockcastle, Piaget rediscovered. Ithaca, N. Y.: Cornell University Press. 
Piaget, J. (1964b). Relations between affectivity and intelligence in the mental development of the child. En Sorbonne courses.

Piaget, J. (1965). Psychology and philosophy. En B. Wolman (ed.), Scientific psychology. Nueva York: Basic Books.

Piaget, J. (1970a). Abriß der genetischen Epistemologie. Stuttgart: Klett-Gotta.

Piaget, J. (1970b). The child's conception of movement and speed. Londres: Routledge and Kegan Paul.

Piaget, J. (1971a). The theory of stages in cognitive development. En D. R. Green, M. P. Ford, G. B. Flamer (eds.), Measurement and Piaget. Nueva York: McGraw-Hill.

Piaget, J. (1971b). Psychologie der intelligenz. Olten: Walter.

Piaget, J. (1972). Psychology and epistemology: Towards a theory of knowledge. Harmondsworth, Inglaterra: Penguin.

Piaget, J. (1973). Der Strukturalismus. Olten: Klett-Cotta.

Piaget, J. (1975a). Das Erwachen der Intelligenz beim Kinde. Stuttgart: Klett.

Piaget, J. (1975b). Der Aufbau der Wirklichkeit beim Kinde. Stuttgart: Klett.

Piaget, J. (1975c). Nachahmung, Spiel und Traum. Stuttgart: Klett.

Piaget, J. (1975d). Die Entwicklung des Erkennens, II. Das physikalische Denken. Stuttgart: Klett.

Piaget, J. (1976). Die Äquilibration der kognitiven Strukturen. Stuttgart: Klett.

Piaget, J. (1978). Das Weltbild des Kindes. Stuttgart: Klett.

Piaget, J. (1979a). Sprechen und Denken des Kindes. Düsseldorf: Schwamm.

Piaget, J. (1979b). Correspondences and Transformations. En F. B. Murray (ed.), The impact of piagetian theory: On education, philosophy, psychiatry, and psychology. Baltimore: University Park Press.

Piaget, J. (1980a). Experiments in contradiction: Chicago: University of Chicago Press. Piaget, J. (1980b). Die Bildung des Zeitbegriffs beim Kinde. Stuttgart: Klett.

Piaget, J. (1983a). Das moralische Urteil beim Kinde. Stuttgart: Klett.

Piaget, J. (1983b). Piaget's theory. En W. Kessen (ed.), Handbook of Child Psychology. Nueva York: J. Wiley.

Piaget, J. (1986). Essay on necessity. Human Development, 29(6), 301-314. 
Piaget, J. (1987). Possibility and necessity. Minneapolis: University of Minnesota Press.

Piaget, J. y Garcia, R. (1991). Toward a logic of meanings. Hillsdale, N. J.: Erlbaum.

Popper, K. (1935). Logik der Forschung. Tubinga: Mohr Siebeck.

Putnam, R. (1993). Making democracy work: Civic traditions in modern Italy. Princeton: Princeton University Press.

Reese, H. W. y Overton, W. F. (1970). Models of development and theories of development. En L. R. Goulet y P. B. Baltes (eds.), Life-span developmental psychology: Research and theory (pp. 116-149). Nueva York: Academic.

Reese, H. W. (1982). A comment on the meanings of 'Dialectics'. Human Development, 25(6), 423-429.

Russell, B. (1931). The scientific outlook. Londres: George Allen y Unwin.

Schwemmer, O. (1980). Dialektik. En J. Mittelstraß (ed.), Enzyklopädie, Philosophie und Wissenschaftstheorie (pp. 463-468). Manheim: Bibliographisches Institut -Wissenschaftsverlag.

Sánchez, A. (2009). Das Selbst der Hypnose y Der Strukturgenetische Ansatz. Berlín: Weißensee Verlag.

Sánchez, A. y Pastrana, B. (2012). El enfoque neoconstructivista y el Estado internacional. Manuscrito interno. Bogotá: Pontificia Universidad Javeriana.

Stenzel, J. (1931). Studien Zur Entwicklung der Platonischen Dialektik von Sokrates Zu Aristoteles: Arete Und Diairesis Mit Einem Anhang, Literarische Form Und Philosophischer Gehalt des Platonischen Dialoges. Stuttgart: Teubner.

Wiesner, J. (1987). Aristoteles. Werk und Wirkung. Berlín: De Gruyter.

Wittgenstein, L. (1958). Philosophische Untersuchungen. Fráncfort: Suhrkamp. 